التماثلية والتجانسية لمقاومية طبقة تحت الأساس لطرق مختارة في محافظة نينوى، شمالي العرق

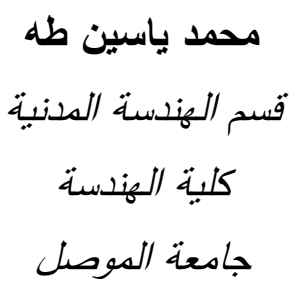

$$
\text { (تاريخ الاستلام 2018/11/4 ، تاريخ القبول 2019/3/4) }
$$

\title{
الملخص
}

لغرض التعرف على طبيعة نطاق طبقة نحت الاساس (Sub-base) للطرق المنشأة، اجريت الدراسة

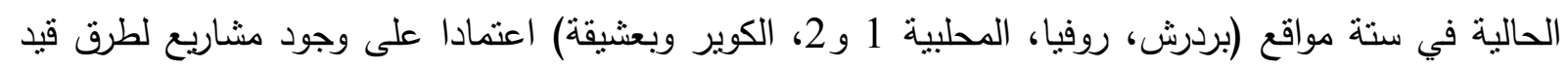

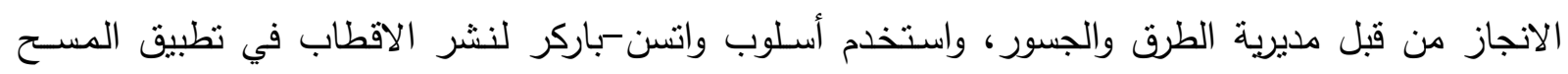

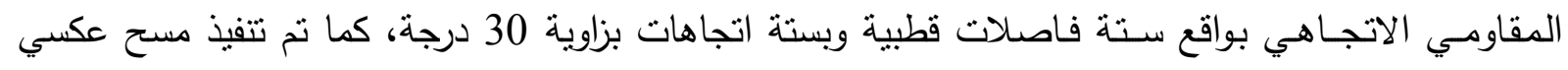
حول نفس نقطة الجس بالاتجاهات الستة.

تم حساب بيانات نسب المقاومة (R1, R R بمرتنمات كارتيزية اتجاهية، ثم درست العلاقة بين الطور والسعة والتردد والانعكاس للمرتسمات الكارتيزية. كما

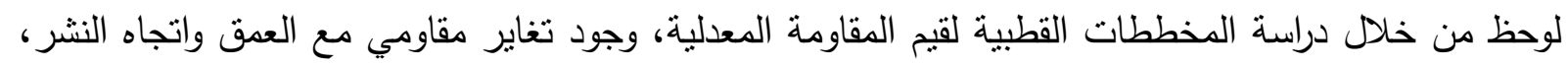

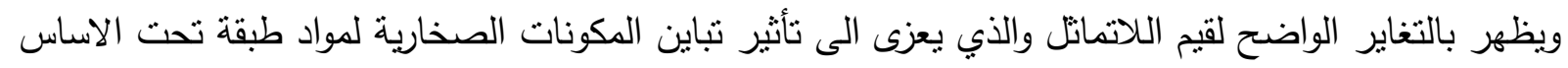

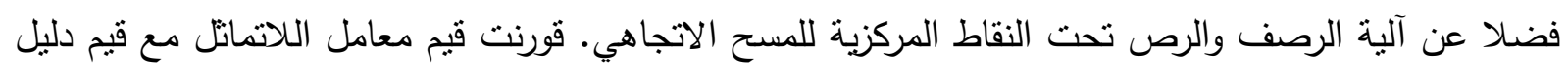

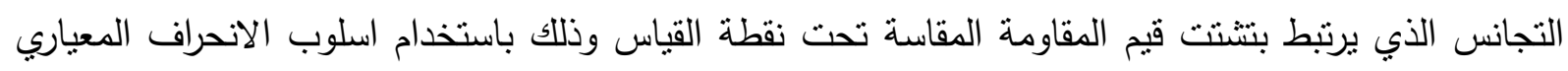
والتي تميز تأثير اللاتجانس للمكونات الصخارية.

الكلمات الدالة: الاتجاهية، المقاومية، المرتسمات الكارتيزية، الاهليليجي، التجانس، اللاتماتلك.

\section{Resistivity Isotropicity and Homogeneity for Sub-base Layer of Selected Roads in Ninevah Governorate, Northern Iraq}

Ali S. Abass Almwaly

Reservoir Engineering Dept.

College of Petroleum and Mining Engineering Mosul University

\section{Marwan Mutib}

Mining Engineering

Dept.

College of Petroleum and

Mining Engineering

Mosul University
Mohammed Y. Taha

Civil Engineering Dept. College of Engineering Mosul University 


\section{ABSTRACT}

Field surveys of electrical resistance are achieved in order to study the sub-base layer of the under constructive roads where the present study is conducted in six locations (Bardarash, Rovya, Mahalabyia 1 and 2, Al-Gwair and Bashiqa) based on the existence of projects for roads under construction by the Directorate of Roads and Bridges. Furthermore, Azimuthal resistivity survey is applied using Parker-Watson array with an electrode spacing and azimuth depending on road directions. Also a reverse surveys are performed on the same points of sounding.

The resistance ratios $\left(R_{\mathrm{d} 1}, \mathrm{R}_{\mathrm{d} 2}\right)$ are then calculated and represented as polar diagrams and cartesian curves. Moreover, analysis relationships are done between the phases, amplitudes, frequencies and their reflections. It is observed from the polar diagrams of the mean resistance values, there is a resistivity variation with the depths and directions of the spread. It is also noticed that there are changes of the Anisotropy Coefficient (AC) values reflecting the effect of the lithofacies contrasts of the sub-base layer belonging to the paving and compacting mechanism underneath the central point of the azimuthal survey. A comparison between AC and Homogeneity Indices (HI) are determined, and the latest values are detected using the standard deviation approach which is thought to reflect the dispersion of measured resistances due to the heterogeneity constitutes.

Keywords: Azimuth, Anisotropy, Homogeneity, Resistivity.

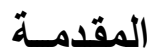

تقع محافظة نينوى في الجزء الثمالي من العراق وتحدها محافظات دهوك شمالاً، اربيل شرقا، كركوك جنوب شرق، تكريت جنوبا والانبار في الجنوب الغربي وترتبط بشبكة من الطرق الرئيسة فضلا عن تفرعات من

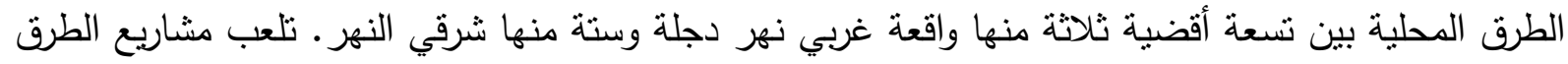

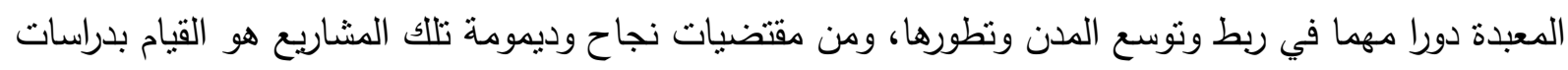
وبحوث علمية تطبيقية بأساليب جديدة لطبقة طرق تحت الأساس (Sub-base) قبل الشروع في تتفيذها وذلك من ونطي خلال استثمار تطور التقنيات الجيوفيزيائية.

تعد تحريات المقاومية الجيوكهربائية (Geoelectrical Resistivity Investigations) واحدة من

الطرق الجيوفيزيائية سريعة التنفيذ وقليلة الكلفة وصديقة للبيئة وغير مدمرة ( Non-Destructive

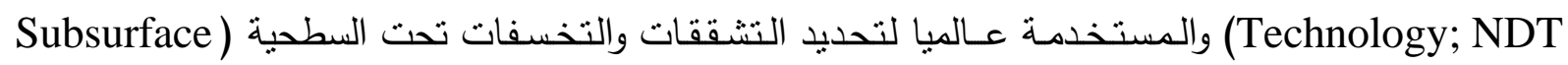
Fractures and Sinkholes

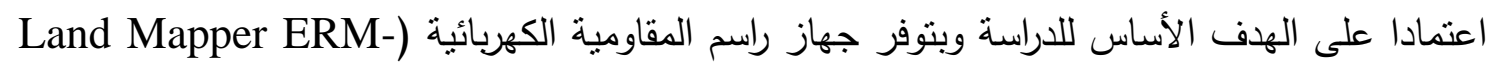
02)، فقد تم اختيار المسح المقاومي ألاتجاهي (Azimuthal Resistivity Survey; ARS) بطريقة واتسنباركر (Watson-Barker Array) لنشر الأقطاب لمواقع متعددة قيد الإنثاء من طرق محافظة نينوى.

تعد الدراسة الحالية مشروعاً ريادياً يخص دراسة طبقة تحت الاساس الترابي (Sub-base Soil)

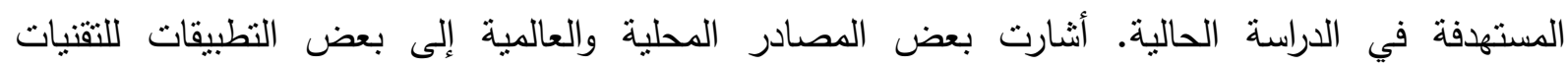
الجيوفيزيائية في هندسة الطرق والتي تخص طبقة التنليط (Pavement) وطبقة الاساس الترابي (Sub-grade). 
أجرى متعب وآخرون (2018) مضاهاة بين معاملات المقاومية الكهربائية وبعض الخواص الهندية لطبقة الأساس الترابي للطرق في محافظة نينوى، شمالي العراق. كما أجرى (Osinowoet al., 2011) دراسة باستخدام تقنية التحري الجيوكهربائي المقاومسي وباسلوب وينر لنشر الاقطاب وتم التعرف على ليثولوجية

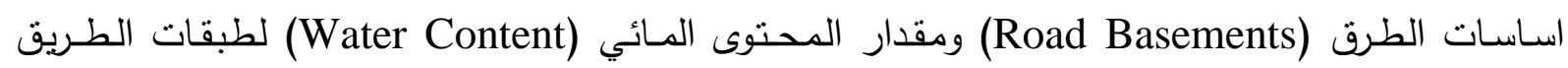
جنوبي غربي نيجيريا. وضع (Victor and Mamah, 2014) موديلا تقربييا لمقاومية الصخور تحت سطح طريق (UHIELE - OPOJI) الهوف الرئيس هو دراسة اسباب فثل طبقة التبليط على طول الطريق Road Surface Failure).أثبت (Rasul et al., 2015) Maintained (من مرحلة التخطيط (Planning) والى مرحلة الصيانة الدورية (Construction) Regularly)، حيث تعد من الطرق سريعة التتفيذ وقليلة الكلفة وغير المشوهة لمنطقة المشروع وذات نتائج منميزة وقد تقلل ايضا من كلفة المنشأ نفسه. هدف الدراسة هو اجراء تقييم لأسلوب نرتيب واتسن-باركر باستخدامه في المسح المقاومي الاتجاهي فواصل قطبية صغيرة فوق طبقة تحت الأساس (Sub-base)، وتحليل البيانات وفق الدراسات العالمية في لي لئيل محاولة لفصل وتمييز التراكب بين اللاتمانل وعدم التجانس، وبالتالي محاولة إلغاء الطرق العشوائية في اختيار مواقع النماذج الهندسية في مشاريع الطرق والمأخوذة إلى المختبرات الإنشائية لغرض اجراء الفحوصات اللازمة عليها.

تم اختيار مناطق الدراسـة الحالية اعتمادا على وجود طرق قيد الإنشاء ضمن محافظة نينوى شمالي العراق، إذ تضمنت ستة مواقع غطت الجهات الشرقية والجنوبية والغربية من الطرق الرابطة بين مدينة الموصل واقضيتها والتي تم تسميتها اعتمادا على المناطق الجغرافية وهي موقع بردرش (Bardarash site; Mahalabiya 1and2 site; MHB1 and وموقع روفيا (Rovya site; ROV) وموقع المحلبية (BRD)

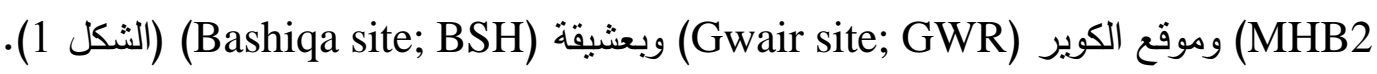




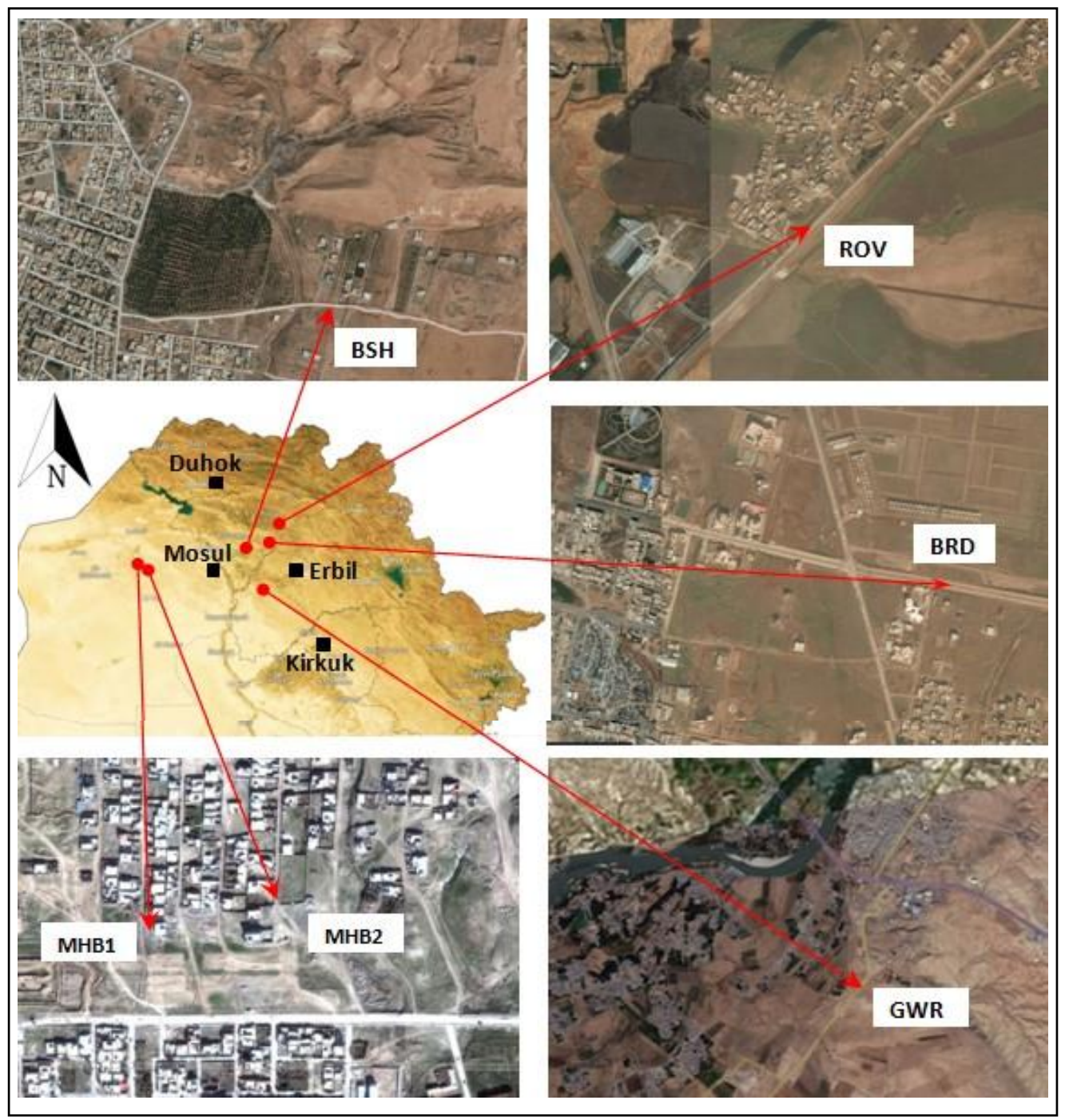

الثكل 1: الجزء الثمالي من العراق مثبتا عليه مو اقع البحث.

\section{منهجية البحث والقياسات الحقلية (Methodology and Field Observations)}

لقد أوصت العديد من الدراسـات العالمية الى ضرورة اعتماد تقنية المسح المقاومي الاتجاهي لتحديد

وتقدير الاتجاهات الرئيسة للاتماتل الكهربائي (Electrical Anisotropy) على وفق كل من (Ratson and) (Barker, 1999 and 2002; Boadu et al., 2005; Slater et al., 2006 و (Odoh and Onwuemesi, 2009) الى أن الصخور غير المتمانلة تتغاير مقاوميتها مع اتجاه النشر. وبذلك فإن أي تغير ملحوظ في المقاومية الظاهرية مع الاتجاه يفسر دليلا على اللاتماثل و / او عدم التجانس الجانبي (Lateral Variation Inhomogeneity). يعد المسح الاتجاهي (ARS) تقنية معدّلة من طرق المسح المقاومي الجيوكهربائي حيث يتم بتدوير

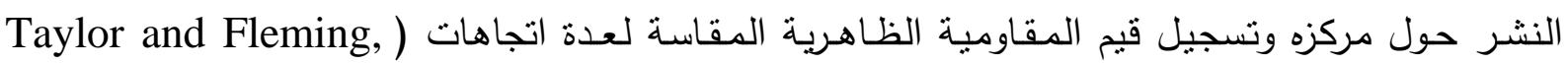
1988). قام (Watson and Barker, 1999) بتطوير تطبيق ترتيب باركر (Barker Array) في تمييز اللاتماتل وعدم التجانس الكهربائي بالاعتماد على المسح المقاومي الاتجاهي، إذ يتم الحصول على دالة زاوية

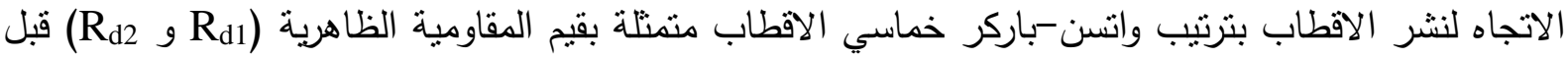


وبعد مركز الدوران على التوالي (الثكل A-2). أكد (Abdullahi et al., 2012) ان أفضل ثقنية نشر للأقطاب للجس بطريقة (ARS) لتحديد مصدر اللاتمانل الكهربائي هي تقنية باركر (الشكل B-2).

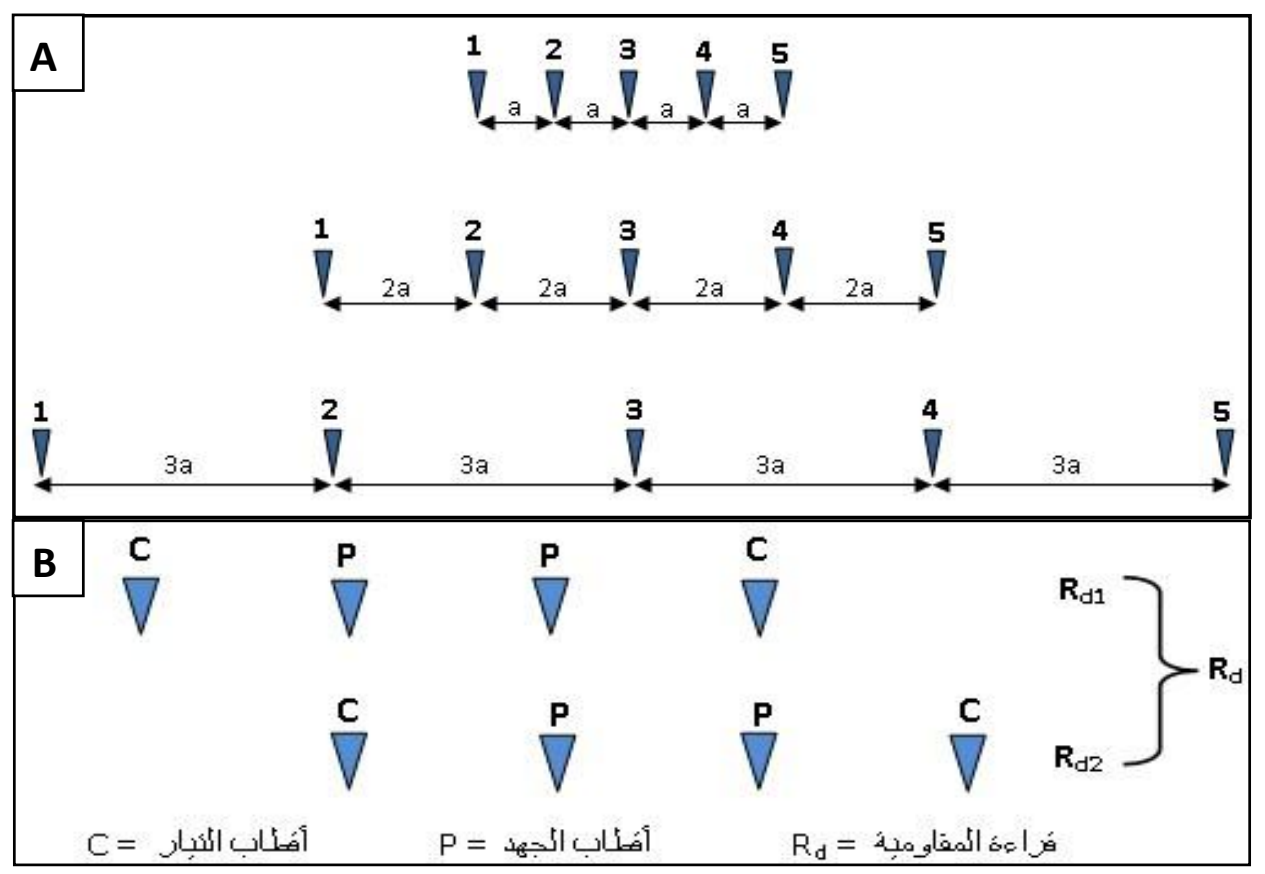

الثكل 2: A -قنية جس و اتسن-باركر خماسي الاقطاب، B-تقنية نشر باركر واسلوب قياس

$R_{d 2} \rho R_{d 1}$

تعد المقاومية الطولية (Longitudinal Resistivity; $\rho_{L}$ (المعامل الاول المؤثر في حساب قيم اللاتماتل للصخور المنطبقة او المكسرة والتي تحدث عبر مستوياتها، اما العامل الثاني المؤثز فهو المقاومية Coefficient of (Transverse Resistivity; $\rho_{T}$ (المستعرضة) ان معامل اللاتمانل الحقيقي (Anisotropy; $\lambda$ الظاهري ( $)$ يعتمد على المقاومية الظاهرية الطولية والمستعرضة.

$$
\lambda=\sqrt{\frac{\rho_{T}}{\rho_{L}}} \ldots \ldots(1), \quad \lambda_{a}=\frac{\rho_{a L}}{\rho_{a T}} \ldots \ldots
$$

ان التباين بين قيم المقاومة المقاسة (Measured Resistance) في المرتسم الكارتيزي لاتجاهات Watson and Barker, ) النشر المختلفة يمكن ان يميز تأثثير اللاتجانس للوحدة الصخرية تحت نقطة القياسي 2002). كما أثنار (Busby, 2000) الى ان النشتت (Dispersion) في قيم المقاومة المقاسة قد بنتج من اللاتجانس في الوحدة الصخرية عندما تكون قيمة التشتت المقاسة أصغر من قيمة اللاتماتل. ويمكن تمثيل هذه الفرضية بالعلاقة الرياضية:

$$
H I=\frac{\sigma\left(\left|R_{d}\right|\right)}{\sigma\left(\left|R_{d 1}-R_{d 2}\right|\right)} \ldots \ldots
$$




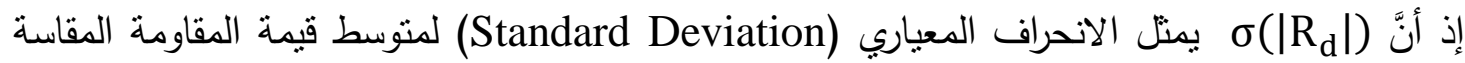
ويمنل $\sigma\left(\left|R_{d 1}-R_{d 2}\right|\right)$ الانحراف المعياري لقيمة الفرق المطلق بين قيمتي المقاومة المقاسة. وتعرف العلاقة Busby, 2000; Abdullahi et al., ) (Homogeneity Index; HI) الرياضية الأخيرة بدليل التجانس .(2012; George and Abong, 2014

يعرف التجانس (Homogeneity) بأنه نوعية انتظام للمادة، فإذا كانت العشوائية موزعة بشكل منساوٍ في خليط المادة فإنها تعتبر متجانسة، اما عدم التجانس (Heterogeneity) فهو نوعية الاختلاف في صفات الصخرة مع الموقع في التكوين الصخري او في طبقة معينة، حيث يؤدي الى حدوث ضوضاء غير منتظمة Busby, ) (Polar Plots) وتتويه قيم المقاومية الكهبائية المقاسة، ويمكن تمييزها بالمخططات القطبية

جمعت بيانات المقاومية الكهربائية الحقلية باستخدام جهاز (LandMapper-ERM02) المطورّ من شركة (Landviser) ذو تقنية حديثة صديق للبيئة يتميز بسهولة استخدامه وخفة وزنه (250غم) وصغر حجمه

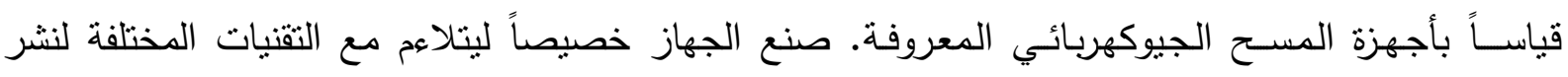
الاقطاب في مسوحات المقاومية الكهربائية. ويمتاز أيضاً بسرعته ودقته الفائقة (99\%) في المسوحات الضحلة التقصيلية (0-10 مثر) وذلك لحساسيته العالية للمقاومية الكهربائية والتغايرات الجانبية والعمودية .(LandMapper, 2012)

يتصف الجهاز بسهولة استخدامه وتتم معايرته مرة واحدة لكل فاصلة قطبية اي انه لا يحتاج الى معايرة مستمرة عند القياس (One Calibration For Each Probe Size)، ويتم تسجيل القراءات في 4 ثوان لكل نقطة وخزن ما يقارب 1000 قراءة في ذاكرة الجهاز • تم تهيئة كافة مسنلزمات العمل الحقلي مع مراعاة ضوابط الاستكثاف الجيوكهربائي منل الابتعاد عن مصادر الضوضاء كأبراج الطاقة الكهربائية عالية الفولتية والابنية الهندسية. كما ثم مراقبة أداء الجهاز والتحقق هراه من فولتية البطارية وتتثيت الاقطاب والتأكد من سلامة الاسلاك وجودة توصيل الاقطاب. استخدم جهاز تحديد الموقع العالمي (GPS) لتعيين الموقع الجغرافي لمناطق الدراسة ولتوثيق احداثيات نقاط المركز ومسارات الجس الكهربائي. اجريت الدراسة الحالية في ستة مناطق متفرقة من محافظة نينوى اعتمادا على وجود مشاريع لطرق قيد الانجاز من قبل مديرية الطرق والجسور في محافظة نينوى، تم استخدام أسلوب واتسن-باركر لنشر الاقطاب في قياس المقاومية الكهربائية وتطبيق المسح المقاومي الاتجاهي. ثم تثبيت الفاصلة القطبية بواقع ستة فواصل

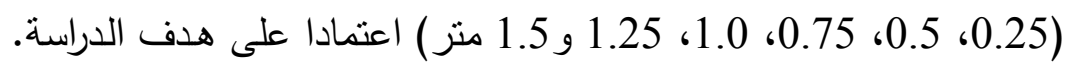

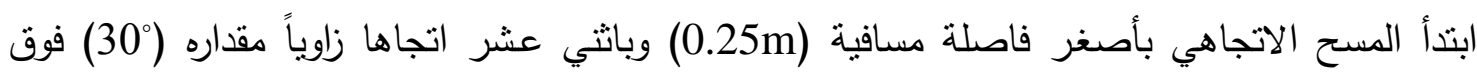

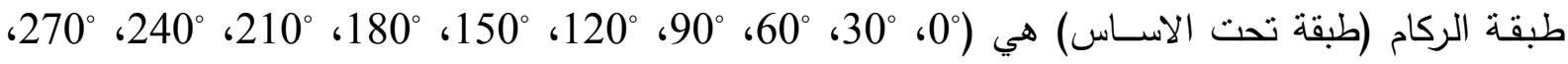

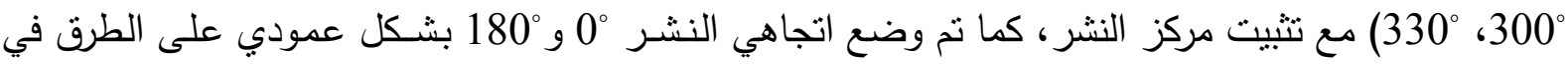
كافة مواقع الدراسة بينما وضع اتجاهي 90 و 270 270 بموازاة الطرق. وتم تسجيل القراءات الحقلية للمقاومـة

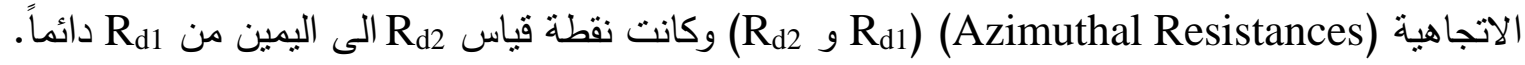




\section{Results and Discussion النتائج والمناقشة}

• • موقع بردرش (Bardarash; BRD)

تقع نقطة المسح المقاومي الاتجاهي في مركز ناحية بردش شرق نهر الخازر والتي تبعد عن مدينة

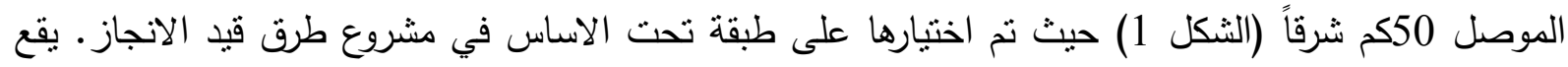
جبل بردرش الى غرب الطريق المدروس اذ تمثل ترسبات طبقة الاساس (Sub-grade) المواد المنقولة من اعالي الجبل المذكور .

مُنلت قيم نسبة المقاومـة الظـاهـرية (Rd1, Rd2) وقيم المقاومة المعدلية (Rdm) على هيئة مخططات قطبية اتجاهية ومرتسمات كارتيزية لاتجاهات النشر بمفاصلات مسافية متعددة وكما موضحة في الثكل (X-3X، Y و Y Y

يتضح مدا تقدم وجود لاتمانل احتوائي ظاهري (Apparent Convoluted Anisotropy) منباين يكون أكثر وضوحا بسعة عظمى مقدارها 118\% باتجاه (60-240) لكل من المسافتين 0.25 و 0.75 بينما يقل وضوح اللاتماتل الالتفافي في الفاصلات القطبية الاخرى. حيث يصبح اتجاهها (90-270ـ) في الفاصلة القطبية 0.5 متز بينما تكون باتجاه (30-210 210 للفواصل 1.0 و 1.25 و 1.5 متر على التوالي (الثكل أشار كل من (Watson and Barker, 1999) و (اقليمس، 2010) الى ان المرتسمات الكارتيزية تعمل على ازالة الالتباس الناتج بفعل اللاتماتل الحقيقي والظاهري والتمبيز بين الكسور والتغايرات الجانبية باستخدام نشر واتسن -باركر • تعد العلاقة بين الطور والسعة والتباين بين منحنيات تمثيل واتسن-باركر الكارتيزية ذات اهمية كبيرة في

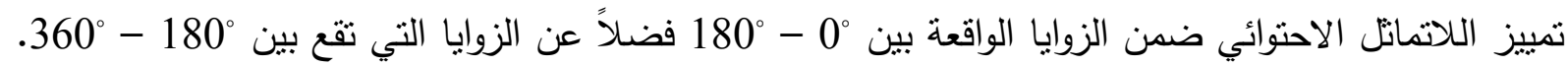

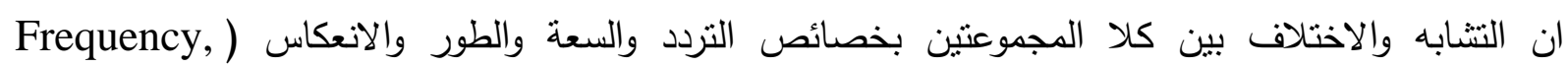
(Amplitude, Phase and Inflection تعكس المرتسمات الكارتيزية للفاصلة القطبية 0.25 متر و 0.5 متر و 1.25 متر تصرفا منتابها نوعا

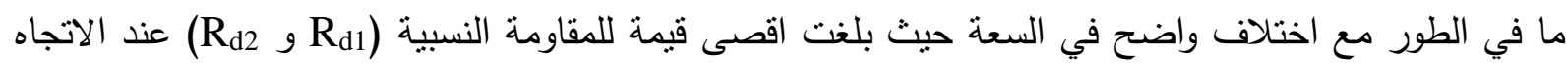

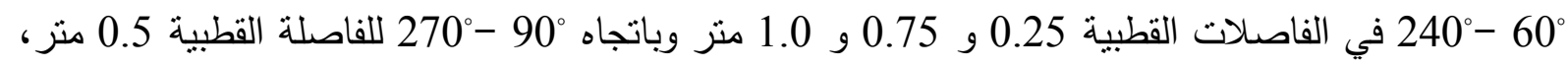

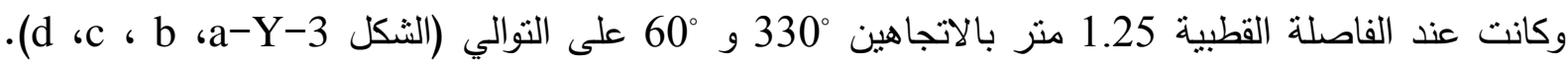
يلاحظ من تصرف المنحنيات الكارتيزية تذبذباً في قيم المقاوميات مما ينعكس على نمط المرتسم الكارتيزي ويظهر عدم انتظام السعات بشكل متميز في اتجاهات النشر كافة. كما وتظهر المرتسمات الكارتيزية للفواصل القطبية 1.25 و 1.5 متز نمطاً مغايرا للفاصلات القطبية السابقة مع اختلاف واضح في السعات وعدم انتظام

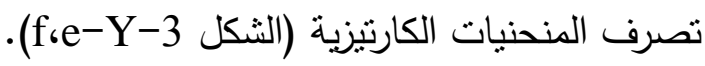




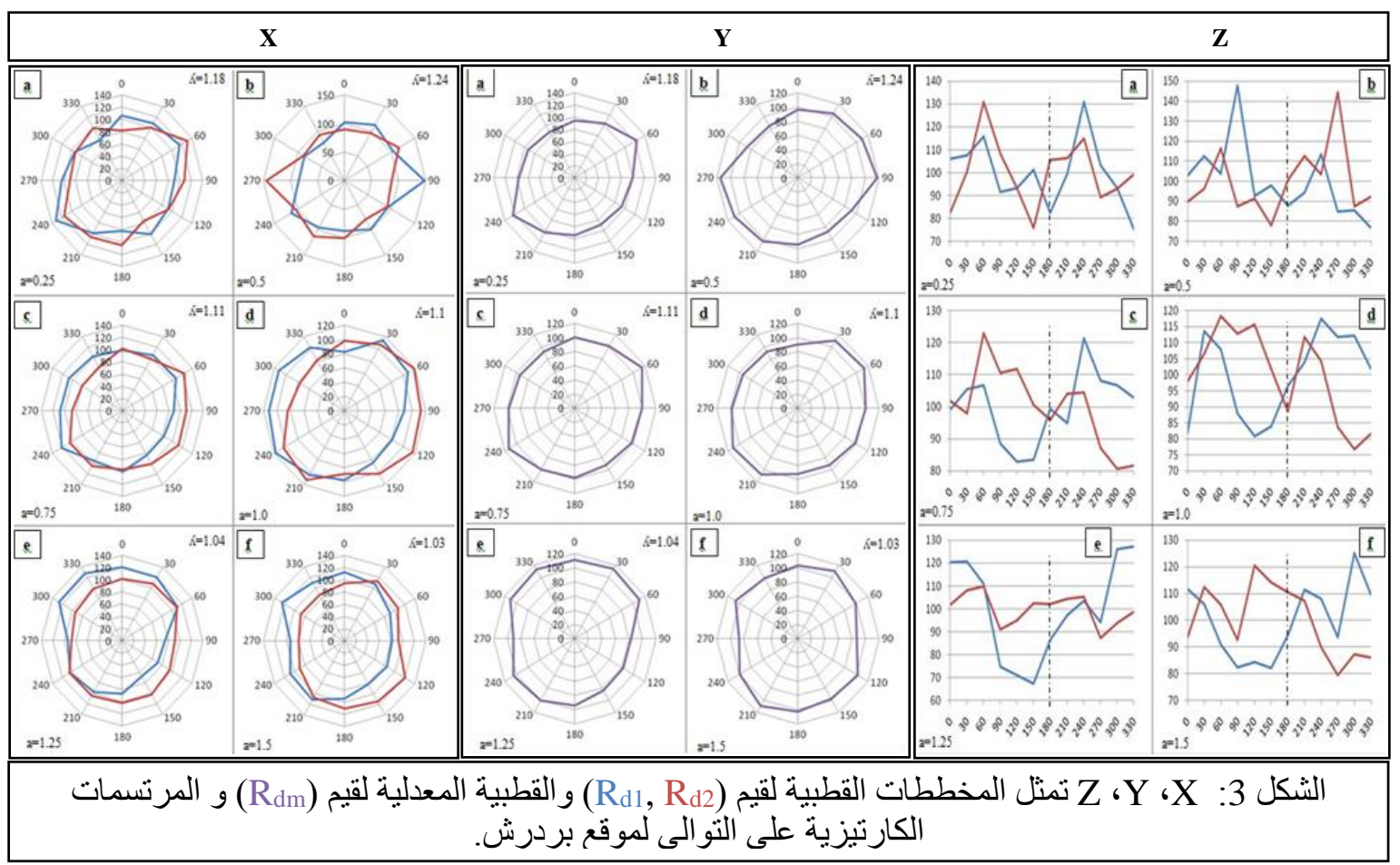

بالرجوع الى دليل التجانس (HI) (الجدول 1) المحسوب وفقا للمعادلة (3)، حيث كانت محصورة بين 0.31 - 0.68 أي أنها (> 1.0) للأعماق كافة، وعلى وفق (Busby, 2000) عندما يكون دليل التجانس أقل من 1.0 فإن الاختلافات في قيم المقاومية الكهربائية مع اتجاهات النشر تكون نتيجة للتغايرات الجانبية أكثر من تأثير اللاتمانل الكهربائي الناتج بفعل وجود الشقوق، كما وتشير قيم المقاومية العالية الى ازدياد الانضغاط التدريجي باتجاه أكبر تغاير جانبي. 
الجدول 1: قيم دليل التجانس واللاتماتل واتجاهها لكل موقع مع الفاصلات القطبية

\begin{tabular}{|c|c|c|c|c|c|}
\hline Location & Spacing/m & $\lambda$ & direction & HI & Effects due to: \\
\hline \multirow{6}{*}{ BRD } & 0.25 & 1.18 & NE-SW & 0.68 & \multirow{6}{*}{ inhomogeneity } \\
\hline & 0.5 & 1.24 & E-W & 0.39 & \\
\hline & 0.75 & 1.11 & NE-SW & 0.38 & \\
\hline & 1 & 1.1 & NE-SW & 0.38 & \\
\hline & 1.25 & 1.04 & NE-SW & 0.59 & \\
\hline & 1.5 & 1.03 & NE-SW & 0.31 & \\
\hline \multirow{6}{*}{ ROV } & 0.25 & 1.45 & $\mathrm{~N}-\mathrm{S}$ & 1.1 & Anisotropy \\
\hline & 0.5 & 1.3 & E-W & 0.56 & \multirow{2}{*}{ Inhomogeneity } \\
\hline & 0.75 & 1.13 & $\mathrm{~N}-\mathrm{S}$ & 0.94 & \\
\hline & 1 & 1.9 & NW-SE & 1.93 & Anisotropy \\
\hline & 1.25 & 1.03 & NE-SW & 0.59 & \multirow{2}{*}{ Inhomogeneity } \\
\hline & 1.5 & 1.45 & $\mathrm{~N}-\mathrm{S}$ & 0.77 & \\
\hline \multirow{6}{*}{ MHB1 } & 0.25 & 1.14 & NE-SW & 0.39 & \multirow{6}{*}{ Inhomogeneity } \\
\hline & 0.5 & 1.14 & NE-SW & 0.52 & \\
\hline & 0.75 & 1.01 & NE-SW & 0.41 & \\
\hline & 1 & 1.02 & NE-SW & 0.57 & \\
\hline & 1.25 & 1.05 & NE-SW & 0.62 & \\
\hline & 1.5 & 1.14 & NE-SW & 0.36 & \\
\hline \multirow{6}{*}{ MHB2 } & 0.25 & 1.1 & NE-SW & 0.4 & \multirow{3}{*}{ Inhomogeneity } \\
\hline & 0.5 & 1.11 & NE-SW & 0.55 & \\
\hline & 0.75 & 1.07 & NE-SW & 0.87 & \\
\hline & 1 & 1.09 & NW-SE & 1.02 & \multirow{2}{*}{ Anisotropy } \\
\hline & 1.25 & 1.05 & NW-SE & 1.39 & \\
\hline & 1.5 & 1.08 & NW-SE & 0.72 & Inhomogeneity \\
\hline \multirow{6}{*}{ GWR } & 0.25 & 1.87 & $\mathrm{~N}-\mathrm{S}$ & 1.05 & Anisotropy \\
\hline & 0.5 & 1.31 & NW-SE & 0.51 & \multirow{2}{*}{ Inhomogeneity } \\
\hline & 0.75 & 1.35 & $\mathrm{~N}-\mathrm{S}$ & 0.7 & \\
\hline & 1 & 1.86 & NW-SE & 1.85 & Anisotropy \\
\hline & 1.25 & 1.06 & NE-SW & 0.49 & \multirow{2}{*}{ Inhomogeneity } \\
\hline & 1.5 & 1.38 & $\mathrm{~N}-\mathrm{S}$ & 0.68 & \\
\hline \multirow{6}{*}{ BSH } & 0.25 & 1.87 & $\mathrm{~N}-\mathrm{S}$ & 1.05 & \multirow{6}{*}{ anisotropy } \\
\hline & 0.5 & 1.48 & NW-SE & 1.29 & \\
\hline & 0.75 & 1.23 & NW-SE & 1.23 & \\
\hline & 1 & 1.36 & NW-SE & 2.16 & \\
\hline & 1.25 & 1.16 & NW-SE & 1.54 & \\
\hline & 1.5 & 1.26 & NW-SE & 1.64 & \\
\hline
\end{tabular}

(Rovya; ROV) • موقع روفيا

تقع نقطة المسح بين ناحية بردرش وناحية روفيا حيث تم اختيارها على طبقة تحت الاساس في مشروع طرق قيد الانجاز على الطريق الرئيسي الرابط بين مدينتي الموصل وعقرة (الشكل 1). مُثلت قيم نسبة المقاومـة

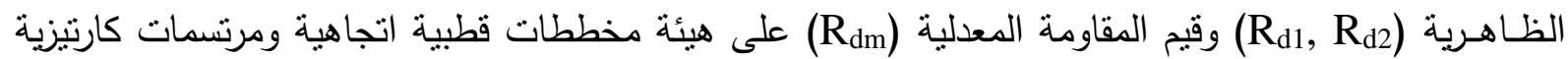

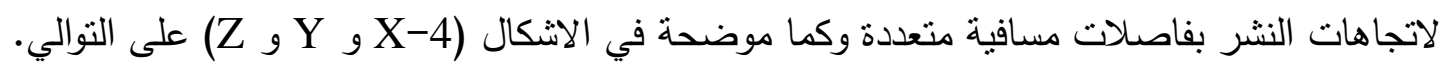
تشير المرتسمات القطبية الناتجة من تمثيل قيم (Rd1, Rd2) الى وجود تغاير في قيم المقاومة مع اتجاه النشر يظهر جلياً في تغاير اتجاهات وانماط الاشكال الإهليجية بزيادة الفاصلة القطبية (الشكل 
الاثكال القطبية بالتصرف التطابقي المعكوس (Reverse Matching) الواضح في جميع الفواصل القطبية مع اختلاف اتجاه محور المقاومة الاعظم، وقد كانت في الفاصلات القطبية 0.25 و 0.75 و 1.5 متز في الاتجاه

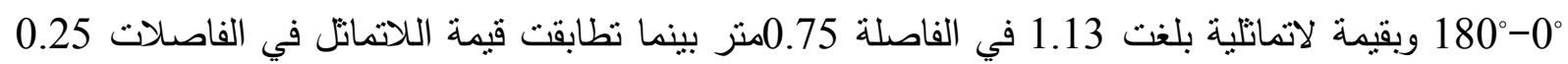

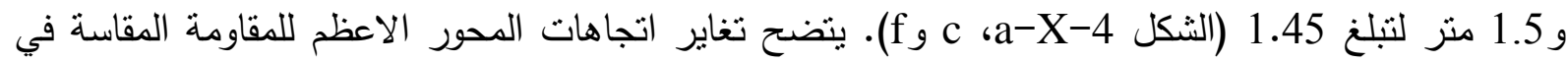

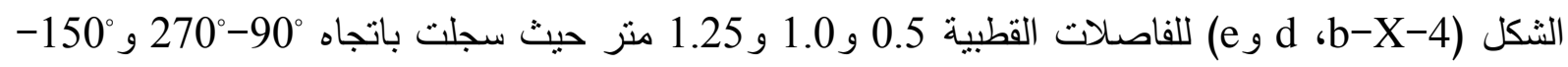

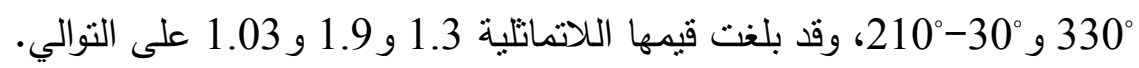
تظهر المخططات القطبية لقيم المقاومة المعدلية (Rdm) بشكل إهليلجي قريب الى الدائري للفاصلات القطبية (0.5 و 0.75 و 1.25) متز (الشكل c cbb-Y-4)، وبتغير اتجاهي المحور الاعظم للأشكال الإهليجية للفواصل القطبية سابقة الذكر من الاتجاه (90-270) عند الفاصلة القطبية 0.5 منر الى الاتجاه

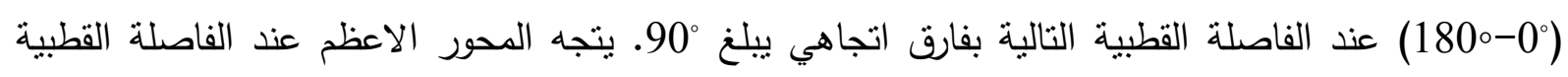
1.25 متر بالاتجاه (210²0 مما يعكس تغاير المقاومة النسبية المقاسة مع العمق واتجاه النشر على الرغم من كون النسبة بين المحورين الاعظم والاصغر ليست عالية. كما وتظهر المخططات القطبية للفاصلات الاخرى لموقع روفيا تغايرا في نمط الثكل الإهليجي واتجاهه ايضا بتعقبد أكثر من سابقتها، (f, d،a-Y-5 الثكل حيث يتجه المحور الاعظم للشكل الإهليجي عند الفاصلة القطبية الاولى (0.25 منز) باتجاه ـ0ـ-180 وبظهر الثكل الإهليجي انضغاطاً واضحا وبشكل معقد نسبيا في الفاصلة القطبية 1.0 منر باتجاه يتضح من تصرف المخططات القطبية لقيم المقاومة المعدلية، وجود تغاير مقاومي مع العمق واتجاه

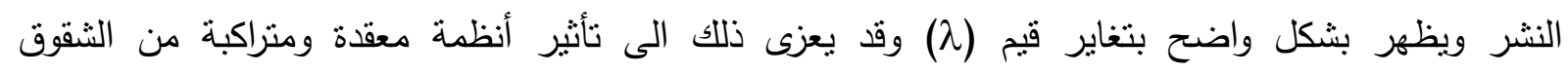

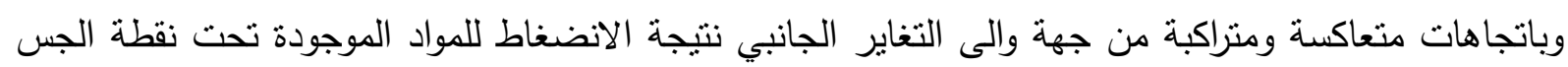
من جهة اخرى.

تدل المنحنيات الكارتيزية في الشكل (Z-4) على ان طبقات الطريق المستكثفة تتصف بالتعقيد غير المنتظم اتجاهاً وعمقاً حيث يتبين من المرتسم الكارتيزي (الثكل

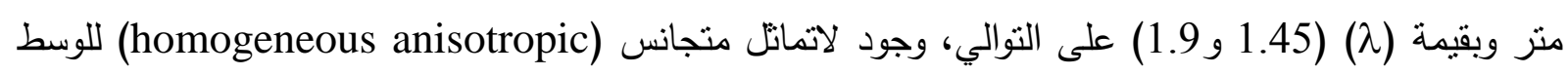

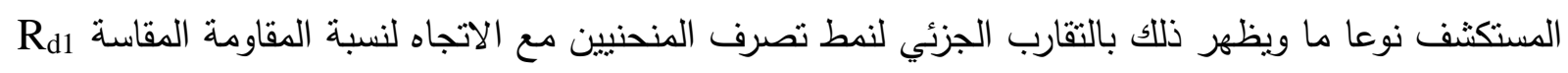

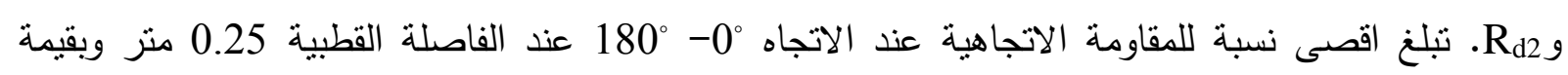

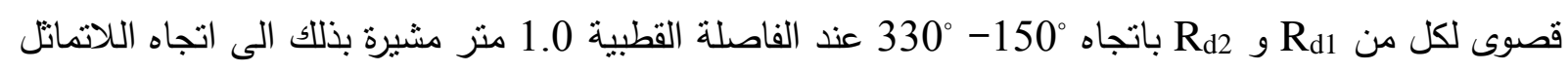
العمودي المتراكب (الثكل daa-Z-4)، بمقارنة قيم معامل اللاتمانل عند الفاصلات القطبية 0.25 و 1.0منر مع قيم دليل التجانس (HI) للفاصلات القطبية نفسها والتي كانت 1.01 و 1.93 يتضح أن التغاير المقاومي عند هذه الاعماق ناتج من تأثثر اللاتماتل المتجانس اكثر من تأثثر التغايرات الجانبية إثارة الى قيمة دليل التجانس HI > 1

يظهر الثكل (f،c،b-Z-4) تصرفا متذبذبا غير منتظم للمنحنيات الكارنيزية في الفاصلات القطبية

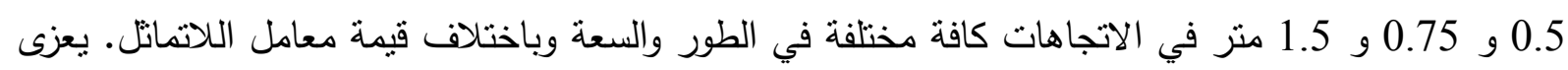
الاختلاف في تصرف المنحنى الكارتيزي غير المنتظم الى تأثنر التغايرات الجانبية او الانضغاط التدريجي للمواد 
المكونة لطبقات الطريق، كما يظهر تأثير اللاتجانس واضحا من قيم دليل التجانس في والتي كانت على التوالي (0.5 و 0.94 و 0.77) في حين يقل التصرف التذبذبي في الطور للمنحنيات الكارتيزية عند الفاصلة القطبية

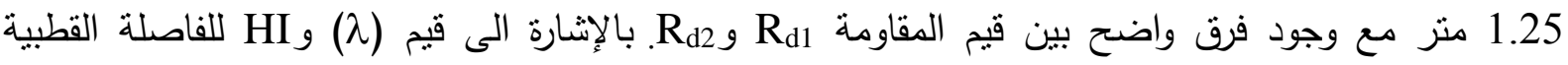

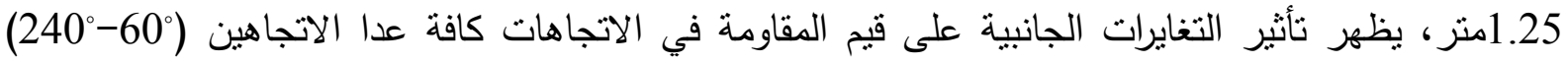
حيث تتساوى قيم المقاومة عندها (الثكل e-Z-4). تعكس قيم معامل اللاتمانل المحصورة بين (1.03 - 1.90) الى وجود تباين منذبذب للاتمانل مع اتجاه نشر الاقطاب من جهة واختلاف الفاصلة القطبية من جهة اخرى، وقد سجلت اعلى قيمة لمعامل اللاتمانل (1.90) عند الفاصلة القطبية 1.0 منز باتجاه نشر (150-1330) درجة في

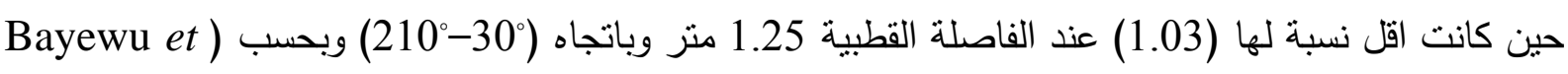
(al., 2014 فإن القيم العالية لمعامل اللاتماتل تتتج من وجود شقوق بأنظمة معقدة ومنراكبة.

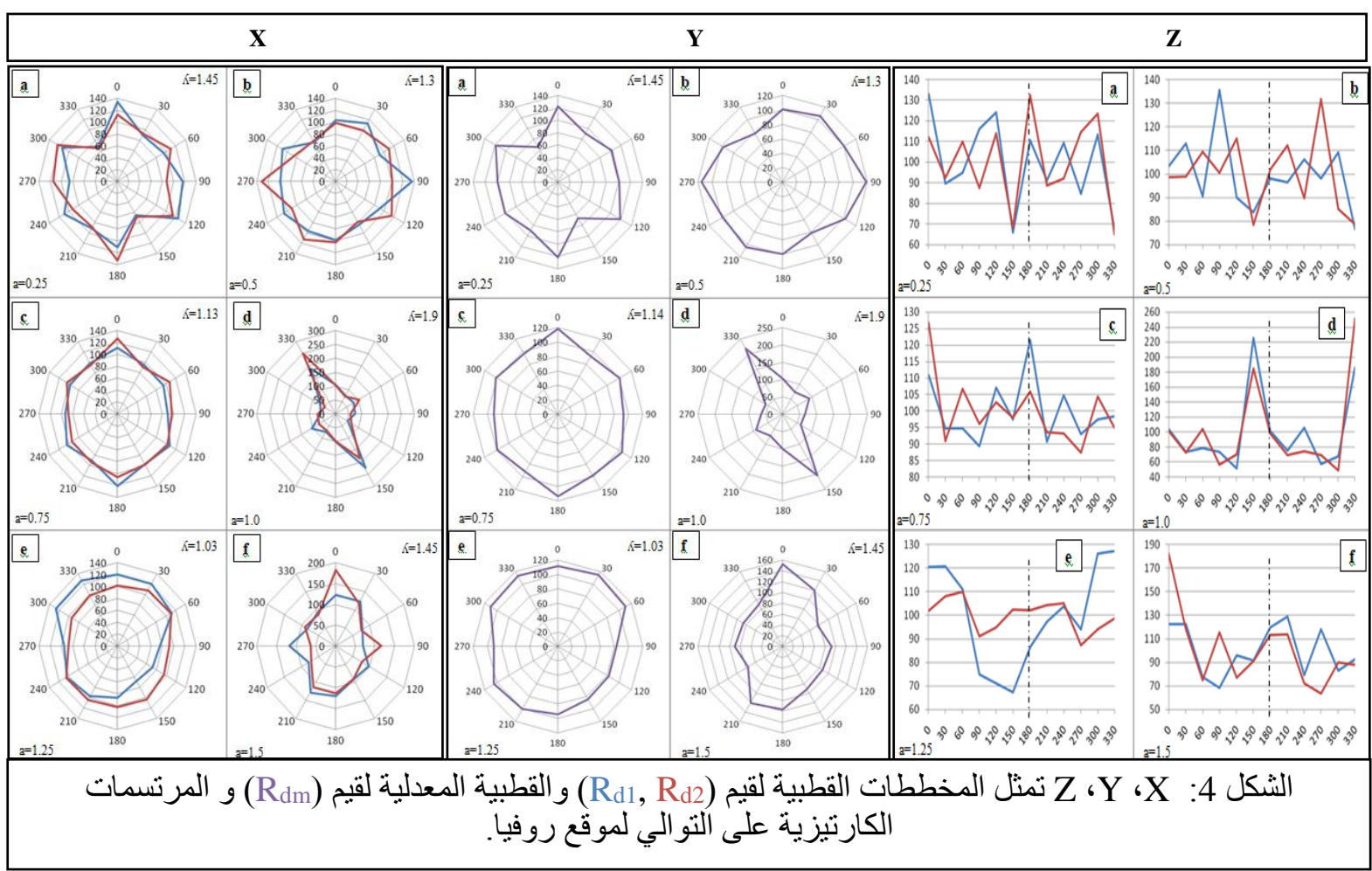

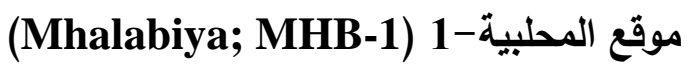

تقع نقطة المسح المقاومي الاتجاهي في مركز ناحية المحلبية على مسافة 40كم غربي محافظة نينوى (الثكل 1) في الساحل الغربي لنهر دجلة حيث نم اختيار نقطة المسح على طبقة تحت الاساس في مشروع انثاء الطرق الفرعية في المنطقة. يقع جبل شيخ ابراهيم بالقرب من الطريق المدروس وتمثل ترسباته المنقولة من اعالي الجبل المذكور مواد طبقة الاساس وتحت الاساس. تم تمثيل قيم نسبة المقاومة المقاسة (R21 and R مخططات قطبية اتجاهية ومرتسمات كارثيزية لاتجاهات النشر بفاصلات مسافية متعددة وكما موضحة في

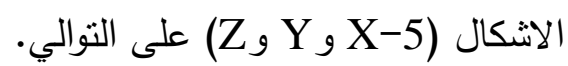


يوضح الثكل (X-5) ستة مخططات قطبية لمسح نسب المقاومة الاتجاهي في موقع المحلبية-1، حيث يلاحظ في الثكل (a-X-5) وجود تتاغم محوري أعظم في الاتجاه 30-210 في الفاصلة القطبية 0.25منز

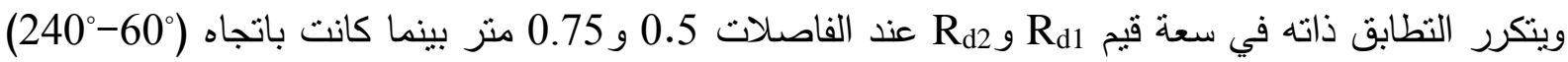
في الفاصلة 1.0 منر في الثكل (d g g g-X-5) على التوالي. اما الفواصل القطبية 1.25 و 1.5 منز فيوضح الثكل (f g e-X-5) اختلاف قيم سعة المقاومة النسبية المقاسة مع اختلاف طوري معكوس واضح بين Rd1 و على الرغم من تطابق اتجاه المحور الاعظم مع الفاصلات القطبية السابقة والتي كانت باتجاه (30$\cdot\left(210^{\circ}\right.$

يتبين من الفحص البصري للأشكال الإهليجية لقيم المقاومة المعدلية (Rdm) (الشكل Y-5)، الانتظام والاتجاه الموحد عند الفاصلات القطبية كافة (NE-SW). ويظهر التطابق التقريبي الواضح للشكل الإهليجي للفاصلات القطبية 0.25 و 0.5 (الشكل b- a-Y-5) وبنفس قيم معامل اللاتمانل (1.14) مما يدل على عدم وجود تغاير يذكر عند هذه الاعماق وقد كانت اعلى نسبة للمقاومة المقاسة R و و Rd1 في الاتجاه ( 210). تقترب المخططات القطبية للفاصلات 0.75 و و 1.0 متر الى الثكل الدائري أكثر من الإهليجي (الشكل و و c-Y-5) و c-Y التوالي. تزداد قيم اللاتماتل بزيادة الفاصلة القطبية (1.25 و 1.5) لتبلغ على التوالي 1.05 و و1.14، وتتعكس هذه الزيادة في اللاتمانل على نمط المخططات الإهليجية للفاصلتين الاخيرتين وباختلاف واضح في النمط والسعة (الشكل e g g e (f) يشير الجدول (1) الى قيم معامل اللاتمانل المحسوبة على وفق المعادلة (2) ودليل التجانس المحسوب وفقا للمعادلة (3) لجميع الفواصل القطبية وبالاتجاهات كافة، وقد انحصرت (ג) بين (1.01 - 1.14) مما نشير الى غياب نأثثر الثقوق تحت نقطة القياس بينما كان دليل التجانس ( 1 ( 1 ) مما يؤكد غياب تأثير الثقوق وبروز تأثير عدم التجانس والتغاير الجانبي على كافة قياسات موقع المحلبية-1 فضلا عن الانضغاط التذريجي للمواد المكونة للانطقة واختلافها مع العمق. تظهر المرتسمات الكارنيزية تصرفاً غير منتظم في السعة مع نشابه جزئي في الطور على الرغم من عدم انتظامه حيث يظهر الانقلاب في قيم المقاومية بعد الاتجاه 150 للفاصلة القطبية 0.25 مثر (الشكل جئ والتي تعكس نقطة التقاطع (Cross-Over point)، كما يتضح عدم انتظام السعات ايضا في المرتسم الكارتيزي للفاصلة القطبية 0.5 منز (الثكل b-Z-5) والتشابه الجزئي في الطور رغم انقلاب المقاومية عند نقطة التقاطع

\section{(Mhalabiya-2;MHB2) 2-2 موقع المحلبية}

تقع نقطة المسح المقاومي بالقرب من موقع المحلبية-1 في مركز ناحية المحلبية (الثكل 1) حيث مُنلت قيم Rd2 و Rd على هيئة مخططات ومرتسمات قطبية اتجاهية وكارتيزية فضلا عن تمثيل قيم المقاومة المعدلية على هيئة مخططات قطبية ايضاً.

يوضح الثكل (X-6) ستة مرتسمات قطبية لمسح نسب المقاومة الاتجاهي في موقع المحلبية-2، اذ يلاحظ في الثكل (a-X-6) تباين في سعة قيم Rd1 و Rd عند الفاصلة القطبية 0.25منز وباتجاه محوري 
أعظم (30-210²)، مع اختلاف واضح في نمط الثكل الإهليجي. يتتاغم الاتجاه المحوري الاعظم في الاتجاه (240²0 (240 بزيادة الفاصلة القطبية (0.5 منز) مع تطابق جزئي لسعة نسب المقاومة المقاسة فضلا عن انتظام تقريب في الثكل الإهليجي لنسب المقاومة (الثكل

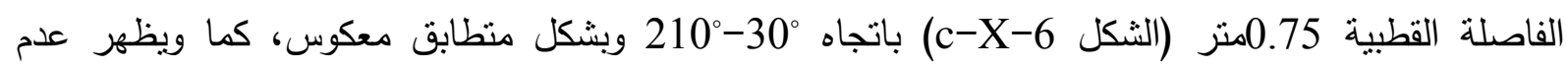
الانتظام في الثكل القطبي (d-X-6) عند الفاصلة القطبية 1.0 منز مع تطابق السعات في بعض الاتجاهات السمنية. يوضح الثكل (e-X-6 و f) زيادة التعقيد والتراكب في الانماط القطبية في الفاصلة القطبية 1.25 و 1.5 منر على التوالي، حيث يلاحظ عدم انتظام الثكل الاهليجي واختلاف سعة نسب المقاومة في اتجاهات

يوضح الثكل (Y-6) المخططات القطبية المعدلية لنسب المقاومة الاتجاهي حيث يظهر فيها تغاير نمط الثكل الإهليجي المنتظم تقريبا في الفاصلات القطبية 0.25 و 0.5 مثر (الثكل a-Y-6 و b)، الى انماطا غير منتظمة عند الفاصلات القطبية 0.75 و 1.0متر (الشكل c-Y و d). يزداد تعقيد المخططات القطبية بزيادة الفاصلات القطبية لتتراكب عند 1.25 و 1.5 منر كما في الشكل (f- و و fe-Y). يتضح مما تقدم تداخل وتراكب ثأثير عدم التجانس مع تأثثر اللاتماثل عند الفاصلات القطبية 1.0 و 1.25 و 1.5 متر والذي قد يعزى الى تداخل نرسبات طبقة الاساس مع ترسبات التربة نتيجة لازدياد الضغط التدريجي مع وجود التغاير الليثولوجي بين النطاقين. يمثل الجدول (1) قيم اللاتمانل ودليل التجانس لموقع المحلبية-2، اذ يلاحظ من قراءة قيم (ح) المحصورة بين 1.11 - 1.05 أن هنالك تأثير ضعيف في سلوك اللاتماتل الكهربائي الناتج من التشققات بشكل طفيف مع العمق. يعكس الشكل (Z-6) المرتسمات الكارتيزية الستة لموقع المحلبية-2، حيث يشير الثكل (a-Z-6) للفاصلة القطبية 0.25 متر الى وجود تغاير واضح في الطور لمعظم الاتجاهات مع اختلاف في السعة في جميع الاتجاهات تقربيا. تم قياس اعلى مقاومة Rdd R R (120) عند الاتجاه 30 في حين كانت اعلى قيمة للمقاومة

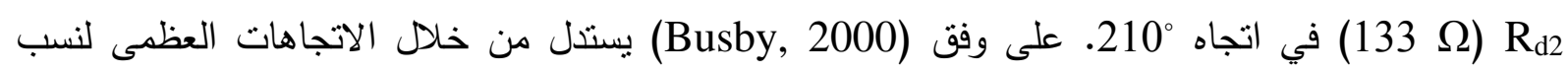
المقاومة المقاسة على اتجاه أعظم تغاير جانبي من قيمة دليل التجانس اقل من 1.0، حيث كانت

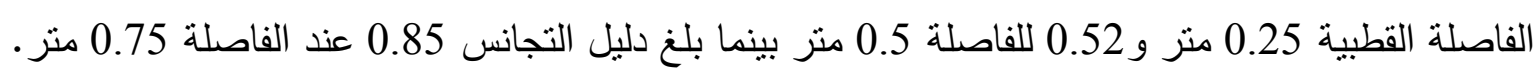

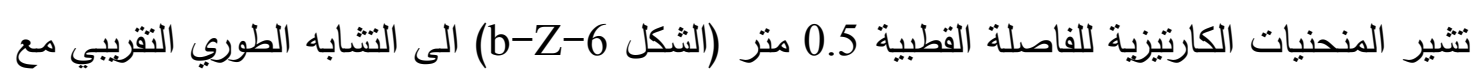
بقاء اختلاف السعة بتغير اتجاه النشر، ويظهر ايضا تغير موقع نقطة التقاطع كما في الفاصلة القطبية السابقة والتي تتساوى عندها قيم المقاومية الى الاتجاهين 90 و 270 وقد بلغت (100/110 اوم) على التوالي والذي يكون بموازاة الطريق وبقيمة لاتماتلية بلغت 1.11، فضلاً عن التطابق النسبي الملحوظ في تسجيل اعلى قيمة

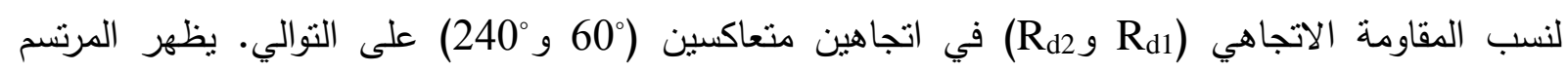
الكارتيزي للفاصلة القطبية 0.75 منز (الثكل كما تتقاطع المنحنيات الكارتيزية في خمسة مواقع مشيرة الى تذبذب قيم المقاوميات وعدم انتظامها مع اتجاه نشر الاقطاب. حسبث قيمة دليل التجانس عند الفاصلة القطبية 0.75 مثر (HI=0.87)، وتظهر زيادة دليل التجانس 
مع العمق ازديادا في الانضغاط باتجاه التغاير الجانبي الغير منتظم يقابلها انخفاضاً في قيمة معامل اللاتمانل (1.07) عما كانت عليه في الفاصلات القطبية السابقة. يمثل الثكل (e،d-Z-6 ) المرتسم الكارتيزي للفاصلات القطبية 1.0 و 1.25 منز وبفارق بسبط جداً في قيمة معامل اللاتماتل (1.09 و 1.05) على النوالي، حيث يظهر النتابه في الطور وتقارب السعة بين منحنيات نسب المقاومة في الفاصلتين مع وجود زحف في قيم Rd و Rd مع اتجاه النشر • سجلت أعظم مقاومة (124 اوم) في الاتجاه $60^{\circ}$ و $90^{\circ}$ لقيم Rd2 و Rd2 على التوالي عند الفاصلة القطبية 1.0 منر، بينما اختلفت قيمة المقاومة العظمى للفاصلة القطبية 1.25مثر لتكون (135 اوم) في الاتجاه $90^{\circ}$ /30 على التوالي.

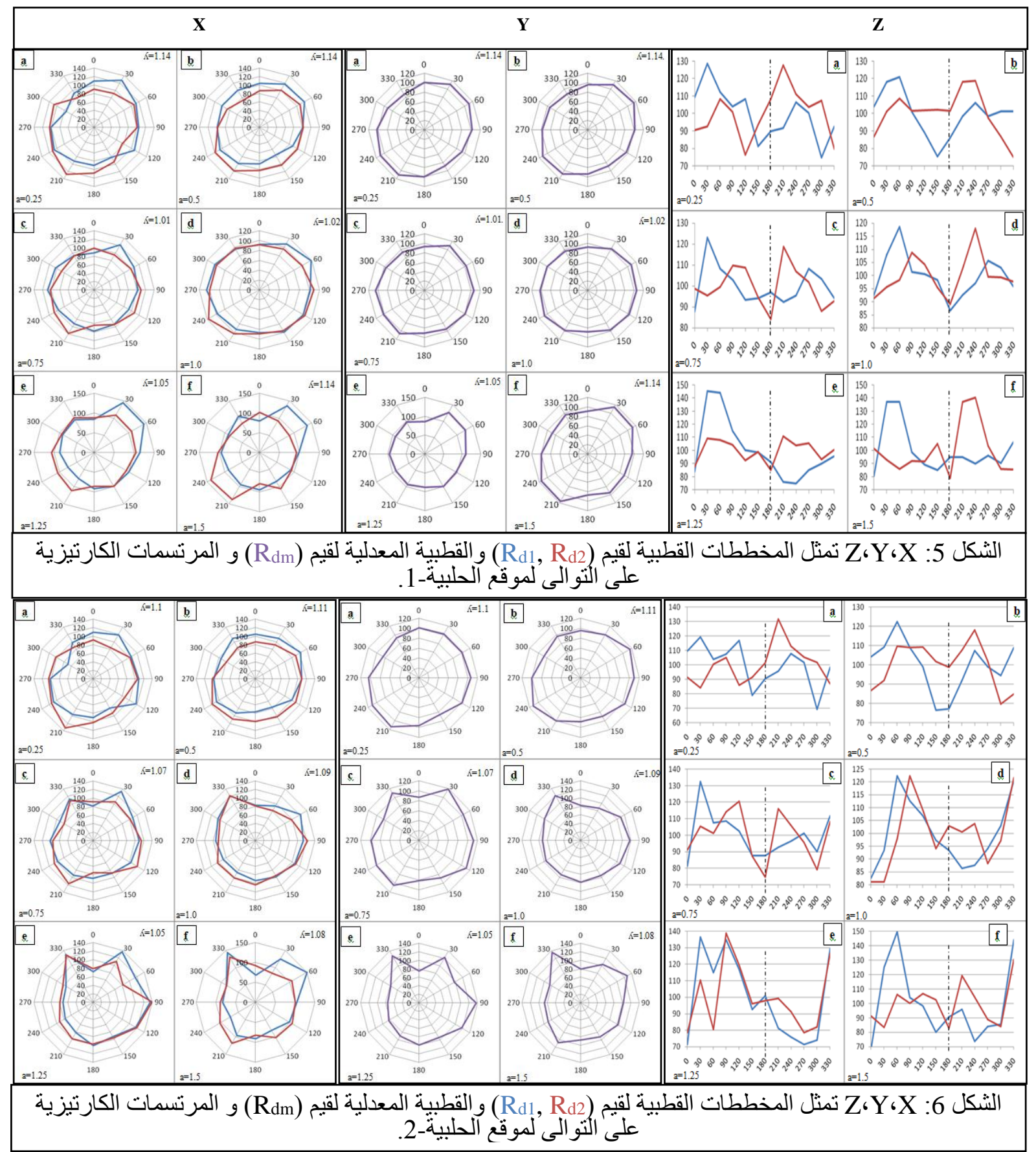


تزداد نسبة الانضغاط التذريجي للمواد مع التغايرات الجانبية بزيادة العمق ويظهر ذلك عند الفاصلة القطبية 1.5منر ، حيث يلاحظ اختلافا متميزا في الطور والسعة للمنحنيات الكارتيزية مع اتجاهات النشر (الثكل

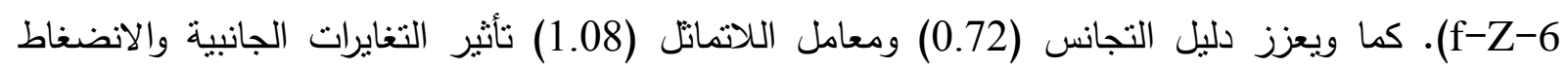
التدريجي للترسبات تحت نقطة القياس والتي ادت الى نشوه الشكل الإهليجي بشكل واضح في المخططات القطبية

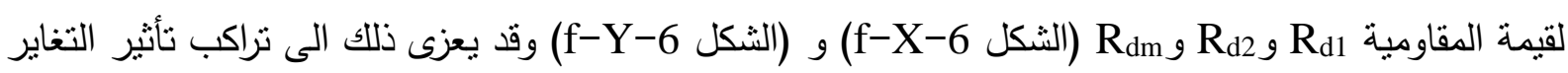
الليثولوجي والجانبي مع الانضغاط التدريجي للتزسبات عند هذا العمق.

\section{• موقع الكوير (Gwair; GWR)}

تقع نقطة القياس قرب ناحية الكوير شرق نهر الزاب الكبير (الثكل 1) شرقي محافظة نينوى، تم اختيار نقطة المسح على طبقة تحت الاساس على الطريق المنشأ لربط القرى القريبة من جبل قرة جوق بالطريق الرئيسي

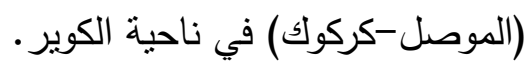

تم تمثيل قيم المقاومة النسبية المقاسة (Rd1 و R Rd2) وقيم المقاومة المعدلية (Rdm) على هيئة مخططات

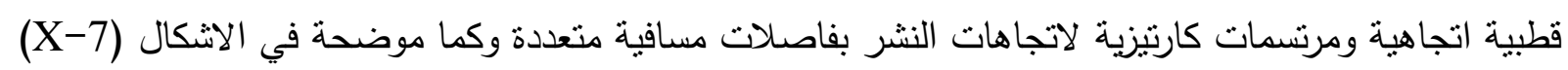
و (Y-7) و (Z-7) على التوالي. فضلا عما تقدم تم حساب مقدار اللاتماثل ودليل التجانس في موقع الكوير عند كل فاصلة مسافية.

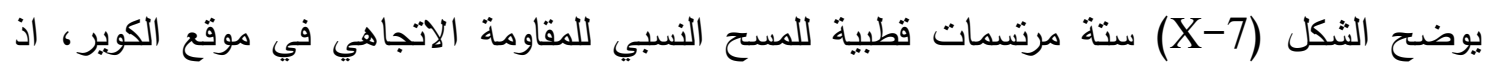
يلاحظ عدم انتظام الاشكال الإهليجية لقيم (Rd1 و و Rd $\mathrm{Rd}_{2}$ في جميع الفاصلات القطبية في هذا الموقع. فضلا عن التطابق المعكوس ماعدا الفاصلة القطبية 1.25متر (الثكل R-X-X) والذي يظهر اختلافا بسيطا في التطابق العكسي عن الانماط القطبية للفاصلات الاخرى.

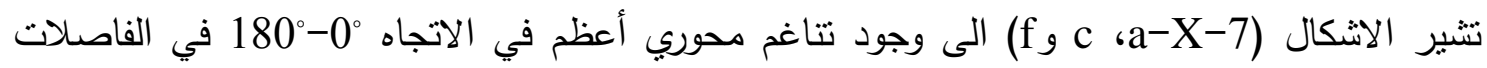

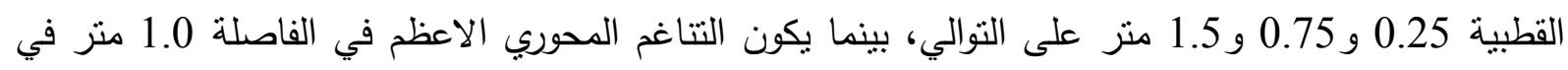

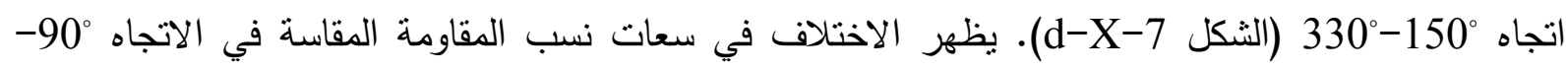

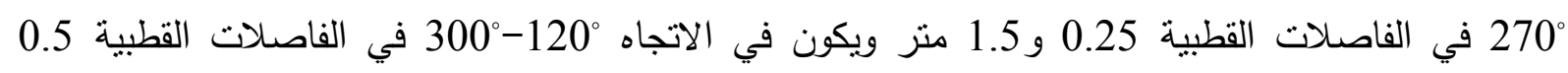

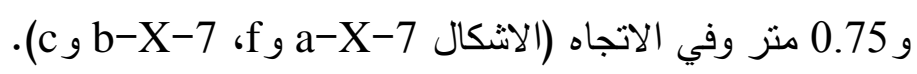

تبرز اتجاهات اللاتماتل بشكل واضح في المخطط القطبي لقيم المقاومة المعدلية Rdm (الثكل

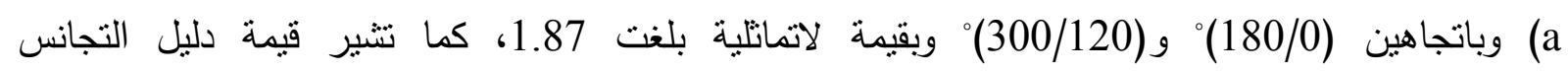
(الجدول 1) الى وضوح تأثير اللاتماتل المتجانس نوعاً ما الى في بعض الاتجاهات المذكورة اعلاه يمكن ملاحظة الاختلاف الطوري بشكل واضح في المخطط القطبي لقيم نسب المقاومة (الثكل

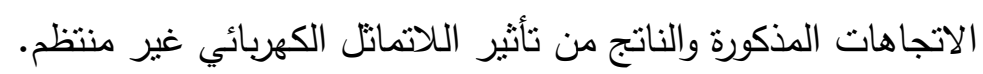

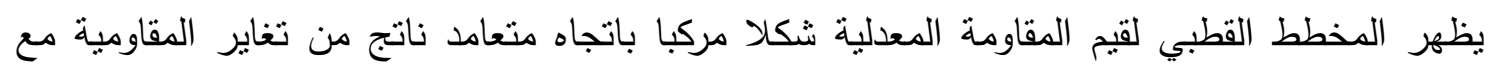

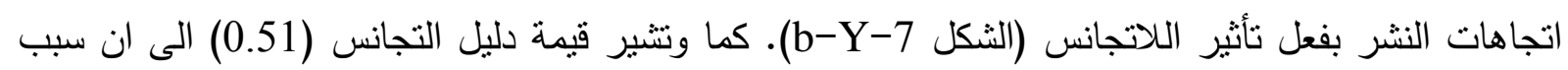
عدم انتظام الثكل الإهليجي واختلافات السعة يعزى الى تأثير التغاير الجانبي والانضغاط التذريجي للمواد على

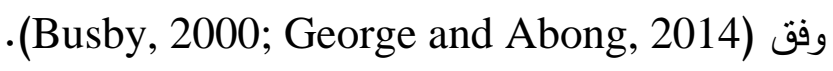
يتضح من المخطط القطبي المعدلي للفاصلة القطبية 0.75 منز (الثكل c-Y-7) اتجاه التغاير الجانبي باتجاهين مختلفين (180/0) و (300/120) اثنارة اختلاف التغايرات الجانبية في اتجاهين مختلفين وبدليل 
تجانس بلغ 0.7، يعزى سبب عدم انتظام تصرف مرتسمات القيم المقاسة الى عدم تجانس تأثثر التغايرات الجانبية

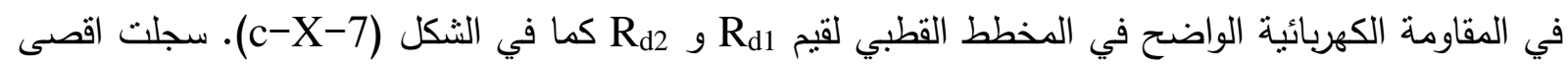
قيم للمقاومة عند 330/150\% حيث بلغت 240 و 250 اوم لقياسات Rd12 و Rd2 على التوالي كما هو واضح في في الثكل القطبي لقيم المقاومة المعدلية (الثكل بحسب (Watson and Barker, 1999) فإن هيئة الثكل الإهليجي ذو الحافات الحادة تؤكد وجود شقوق عمودية تحت نقطة القياس، كما تشير قيمة دليل التجانس والتي بلغت 1.85 الى زيادة تأثير اللاتمانل المتجانس على تأثنر التغايرات الجانبية كما هو واضح من التطابق النسبي في الثكل الإهليجي الحاد في اتجاهات النشر لقيم المقاومات النسبية في المخطط القطبي لقياسات Rd1 و Rd2 (الثكل يتضح من الثكل (f g e-Y-7) عدم انتظام المخطط القطبي لقيم المقاومة المعدلية في الفاصلة القطبية

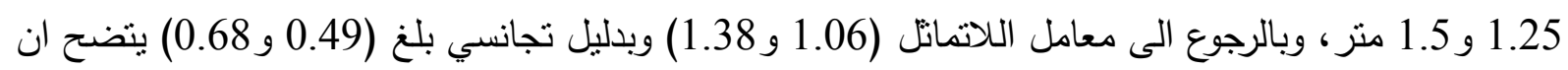

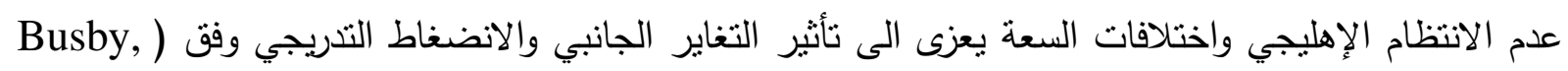
.(2000; George and Abong, 2014 بشكل عام يتضح تأثير معامل اللاتماثل وعدم التجانس بشكل تردد عمودي دوري اتجاهي واضح من مراجعة قيم اللاتماتل وعدم التجانس المذكور في الجدول (1) من جهة ومقارنتها مع المخططات القطبية لنسب

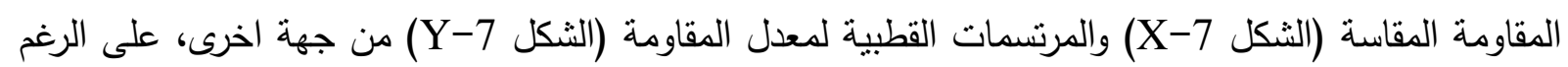

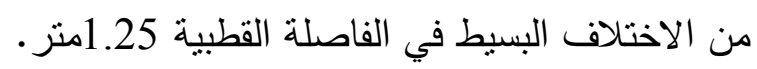

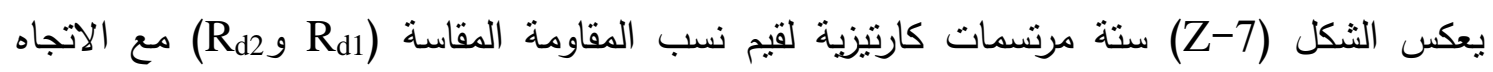
وبفاصلات مسافية متعددة، حيث بمكن معاينة تصرف منحنيات نسب المقاومة بصريا للتعرف على تأثير اللاتماتل او عدم التجانس من خلال ملاحظة انتظام الاطوار والسعات او اختلافها فضلا عن ملاحظة نقاط نقاط الانقلاب ومواضعها نسبة الى اتجاهات النشر والفاصلات القطبية (Watson and Barker 1999). يلاحظ في الفاصلة القطبية 0.25 منز تطابق نسبي في الطور والسعة لمنحنيات القياس في معظم اتجاهات النشر ماعدا الاتجاهات $90^{\circ}$ و 240 و 270 حيث يظهر الاختلاف الطوري واضحا في المرتسم الكارتيزي (الشكل a-Z-7). كما وتشير قيمة دليل التجانس (0.51) الى ان سبب عدم انتظام الشكل الإهليجي

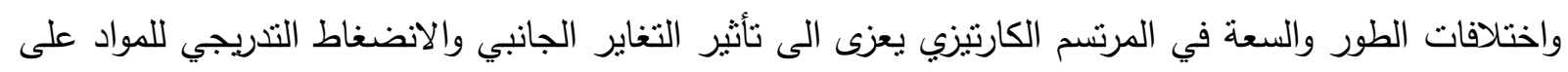
وفق (Busby, 2000; George and Abong, 2014). يبدأ التراكب والتعقيد في القياسات الحقلية مع توسيع الفاصلة القطبية الى المسافة 0.5 مثر، حيث يظهر المرتسم الكارتيزي (الثكل b-Z-7) عدم توافق الاطوار والسعات بشكل مركب ومعقد مع اتجاهات النشر وبقيمة لاتماتلية اقل من الفاصلة القطبية السابقة بلغت 1.31 على وفق (Watson and Barker, 1999). يمنل الثكل (c-Z-7) المرتنم الكارتيزي لقيم المقاومية المقاسة عند الفاصلة القطبية 0.75 منز ، ويظهر اختلافاً في تصرف قيم المقاومية Rd1 و R مبشكل واضح من مقارنة اطوار وسعات المنحنيات الناتجة منها والمحصورة عند

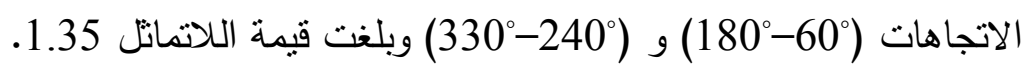
يظهر الاختلاف واضحا عند مقارنة المرتسم الكارتيزي الحالي مع المرتسمات الكارتيزية للفاصلات

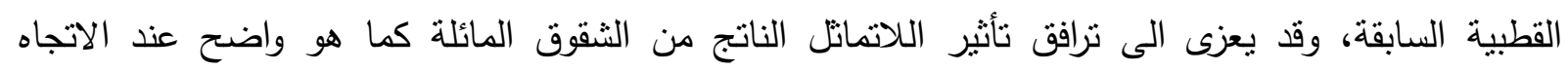

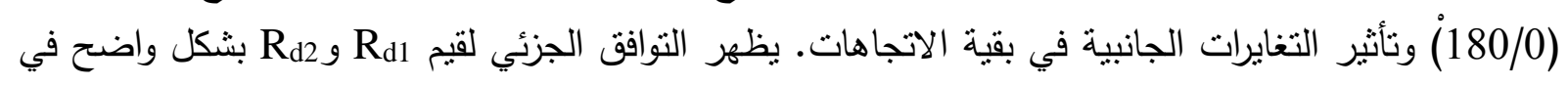

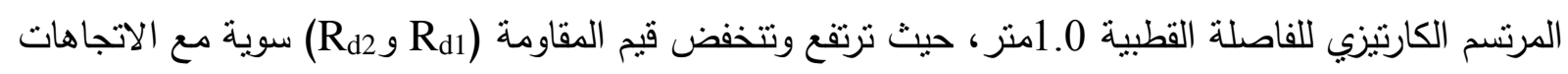


وباختلاف بسيط في السعة عند اتجاه 330/150 درجة مع تسجيل اختلاف طوري بسيط عند الاتجاه 240/60 درجة (الشكل d-Z-7).

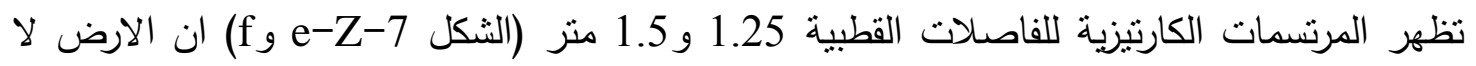
تتصف باللاتماتل بل يعزى عدم الانتظام في قياسات المقاومة (Rd1 و Rd2) مع الاتجاهات السمنية الى التغايرات الجانبية في المقاومة. ويبدو في المرتسم الكارتيزي للفاصلة 1.25 متر أن اقصى تغاير بيني قيم المقاومة

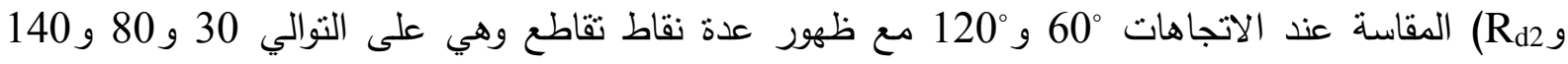

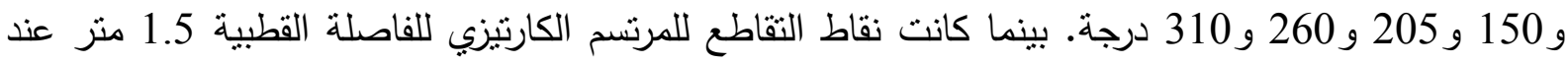

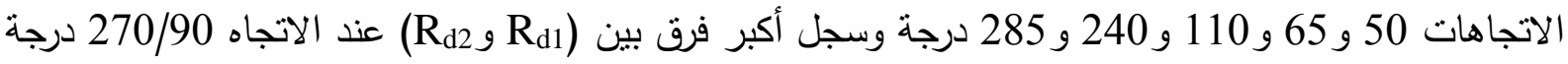
وقد كانت قيمة اللاتماتل 1.06 و 1.38 على التوالي للفاصلات المذكورة، في حين حسبت قيمة دليل التجانس

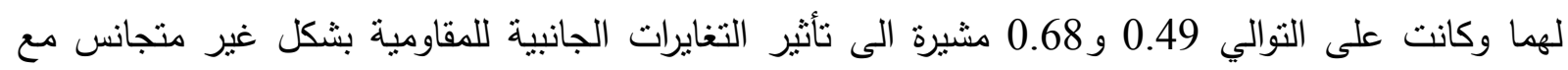
اتجاهات النشر

\section{• موقع بعثيقة (Bashiqa; BSH).}

تقع نقطة القياس المقاومي الاتجاهي في ناحية بعشيقة وعلى طبقة تحت الاساس للطريق الرابط بين مركز الناحية وقرية آجي جوخ غرب نهر الخازر شمالي شرق مدينة الموصل (الثكل 1). يقع جبل بعشيقة غرب نقئ نقية المسح اذ تمثل ترسبات طبقتي الاساس وتحت الاساس المواد المنقولة من اعالي الجبل المذكور .

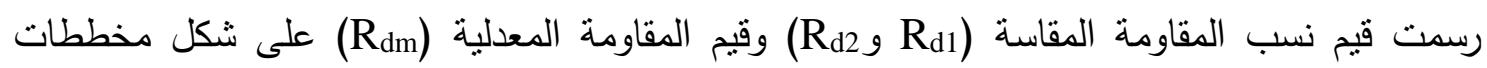

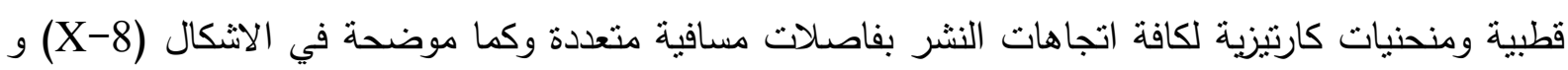

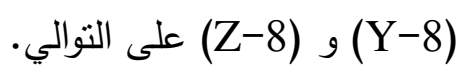

يوضح الجدول (1) قيم معامل اللاتمانل ودليل التجانس المحسوبة لنقة القياس في موقع بعشيقة للفواصل القطبية كافة على وفق التعابير الرياضية (1 و 2 و3) والتي يمكن ان تعطي تصورا اوليا لمدى تأثثر العاملين المذكورين على قياسات المقاومة النسبية المقاسة.

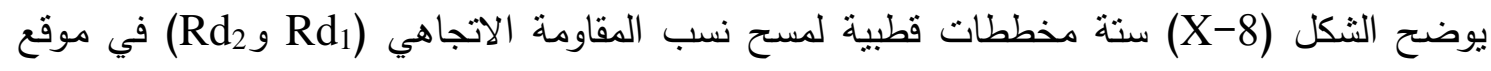

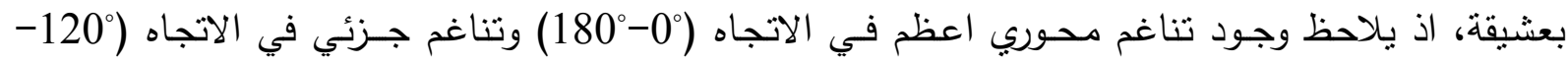

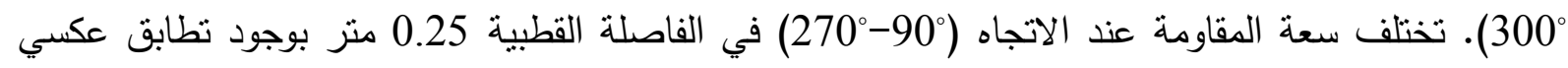
جزئي لقيم المقاومة باتجاه المحور الاعظم (الثكل X-8) وقد بلغت قيم معامل اللاتماتل ودليل التجانس المحسوبة 1.87 و 1.05 على التوالي. يظهر التطابق العكسي في الثكل (b-X-8) حول الاتجاه المحوري (210²0 في الفاصلة القطبية 0.5 منز وبعامل لاتماتلي 1.48 بينما كان دليل التجانس 1.29 1.29، وكان اتجاه أعظم مقاومة (120-300). يلاحظ في الثكل (c-X-8) زيادة حافات الثكل الإهليجي غير المنتظم على

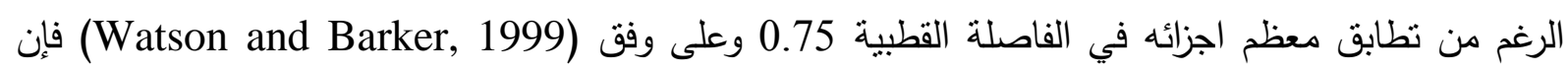
هيئة الثكل الإهليجي ذو الحافات الحادة يؤكد وجود شقوق عمودية تحت نقطة القياس، كما نشير قيمة دليل

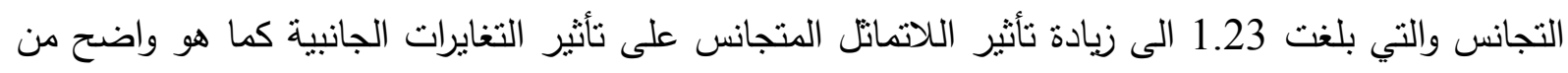
النطابق النسبي في الثكل الإهليجي الحاد في اتجاهات النشر لقيم المقاومات النسبية. يظهر الانطباق شبه التام

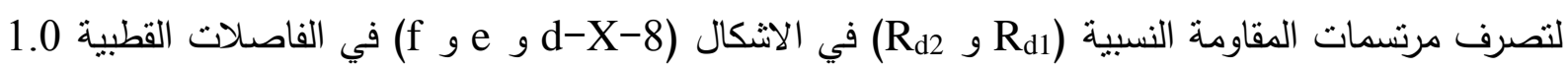
و 1.25 و 1.5 مثر على النوالي، وبالرغم من عدم انتظام الاهليلج القطبي الا ان التتاغم المحوري واضح في ولاني 
الاتجاه (150-330) في الفاصلات الثلاثة مع اختلاف قيم الدليل التجانسي ومعامل اللاتماتل حيث كانت على التوالي (2.16 و 1.54 و 1.64) (1.36 و 1.16 و 1.26) (الجدول 1).
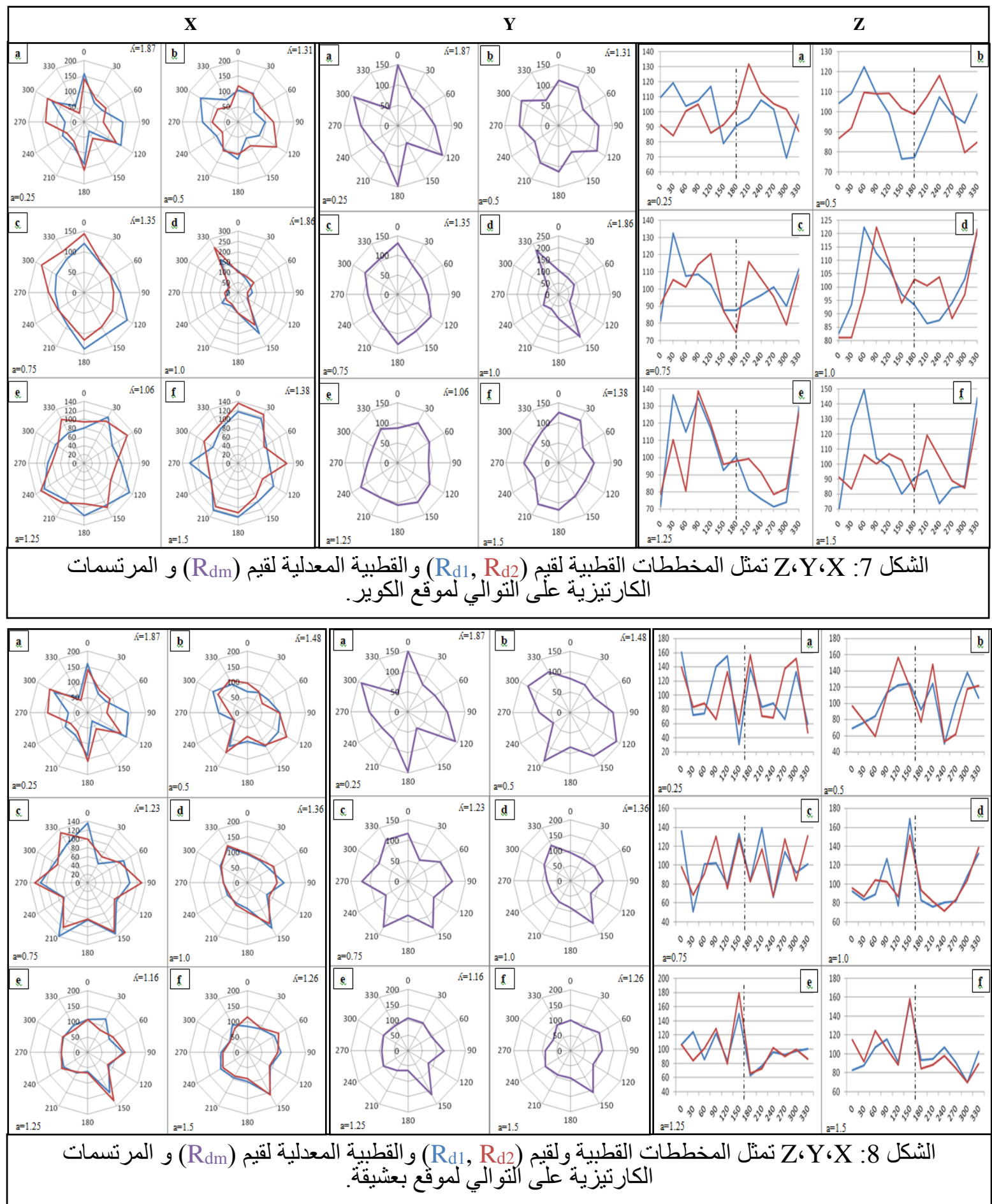

يلاحظ في الثكل (Y-8) التأثثر المترافق للاتماتل وعدم التجانس من ملاحظة المخططات القطبية الستة لقيم المقاومة المعدلية (Rdm) اذ يظهر تشوه وعدم انتظام الثكل الإهليجي واختلاف السعات مع اتجاهات النشر باختلاف الفاصلات القطبية. اشتار (Matias, 2008) الى ان التشوه والتراكب في الثكل الإهليجي مع اتجاه النشر ينتج من تداخل تأثثر اللاتماتل الكهربائي مع التغايرات الجانبية وزيادة نسبة اللاتماتل الى عدم التجانس يمكن اعتبار التأثير ناتج من لانج 
من اللاتمانل غير المتجانس (Inhomogeneously Anisotropic). يمثل الثكل (Z-8) المرتسمات الكارتيزية لموقع بعشيقة حيث تظهر منحنيات الفاصلة 0.25منز تطابقا واضحا بالطور والسعة مع ازاحة بسيطة

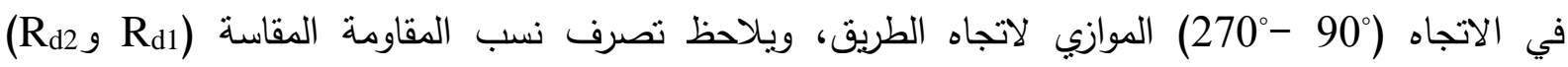
بالارتفاع والهبوط معاً وبنوافق جزئي مع اتجاه النشر بشكل واضح في الشكل (a-Z-8). سجلت سلت اعلى مقاومة

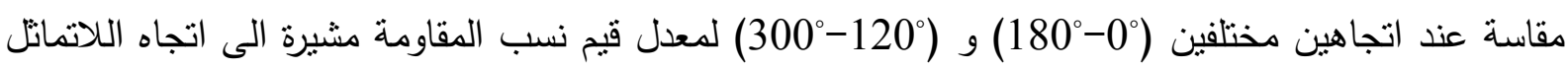
عند الفاصلة القطبية اعلاه وبقيمة لاتمانلية بلغت 1.87، على الرغم من توافق تصرف قيم المقاومة المقاسة والتي

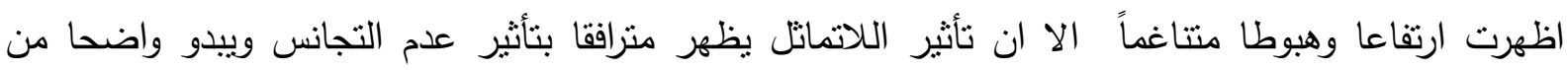
حساب قيم دليل التجانس والتي كانت 1.05 والتي تشير الى تساوي نسبي بين تأثنير اللاتمانل وعدم التجانس حيث ذكر (Abdullahi et al., 2012) عند تساوي قيم اللاتماتل والتشتت فإن ناتج العلاقة الرياضية (3) فئين تساوي 1.0 وتكون التغايرات نتيجة اللاتمانل وتلك الناتجة من عدم التجانس منساوية. نظهر المنحنيات

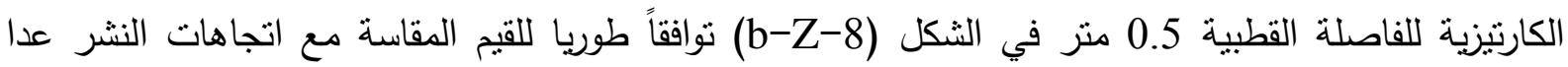
الانعكاس الطوري عند الاتجاه (0) مع الاخذ بنظر الاعتبار اختلاف السعة مع الاتجاه.

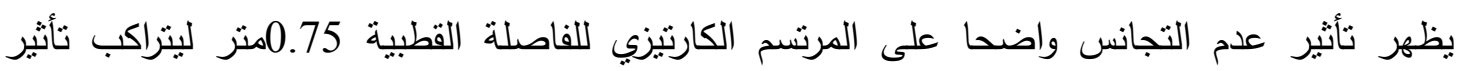
التغايرات الجانبية غير المتجانسة مع تأثير اللاتماتل بدليل تجانس بلغ 1.23، وعلى الرغم من تسجيل تباين

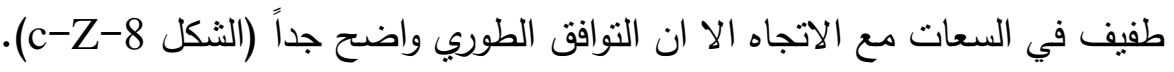

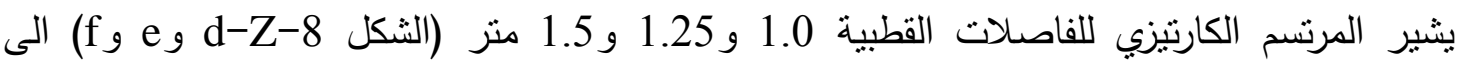
استمرار التتاغم الطوري بالإضافة الى التوافق في السعة مع اتجاهات النشر رغم وجود اختلاف طوري عند الاتجاه $45^{\circ}$ للفاصلة القطبية 1.25 منز ، وقد كانت اعلى قيمة للمقاومة عند الاتجاه $150^{\circ}$ للفاصلات فئلات القطبية الثلاثة وكانت قيم معامل اللاتماتل 1.36 و 1.66 و 1.38 بينما كانت قيم دليل التجانس 2.1 و 1.54 و 1.64 للفاصلات القطبية المذكورة على التوالي.

\section{الاستنتاجات}

أظهرت نتائج الدراسة الحالية لطبقة تحت الاساس لطرق مختارة في محافظة نينوى إمكانية استخدام تقنية باستعمال ترتيب واتسن-باركر خماسي الاقطاب في تحديد التغايرات الجانبية الناتجة من عدم التجانس وتمبيز وجود اللاتمانل الكهبائي فيها من خلال مقارنة معطيات المخططات القطبية والمرتسمات الكارتيزية بفاصلات مسافية متعددة للمواقع الستة في المنطقة المدروسة.

ابرزت المخططات القطبية الناتجة من تمثيل قيم (Rd1, Rd2) لمواقع الدراسة ان معظم الاشكال القطبية الاتجاهية تظهر شكلا اهليليجيا وليس دائرباً لكن تبقى نسبة المحور الطويل الى المحور القصبر أكبر من الواحد بقليل وبذلك فإنها تشير الى غياب الثقوق عند تلك الاعماق المستكثفة. بشكل عام يظهر بوضوح ان هنالك تغايرا غير منتظم في المقاومة في اتجاهات النشر كافة وللفاصلات القطبية جميعها وقد يعزى ذللك الى اللاتماتل الغير متجانس (Inhomogeneous anisotropy) بينما اكدت هيئة الشكل الإهليجي ذو الحافات الحادة وجود شقوق عمودية بامتدادات واتجاهات مختلفة. 
وتوصي الدراسة باستثمار تقنيتي ARS و قبل عملية اكساء الطرق بطبقة التبليط فضلا عن

استخدامها لأعمال الصيانة الدورية لدورها البارز في الكثف عن مقدار اللاتماثل وتحديده وايجاد مناطق بطاه التغايرات الجانبية غير المتجانسة المتسبية في رداءة الطرق وحدوث التخسفات والتشققات فيها.

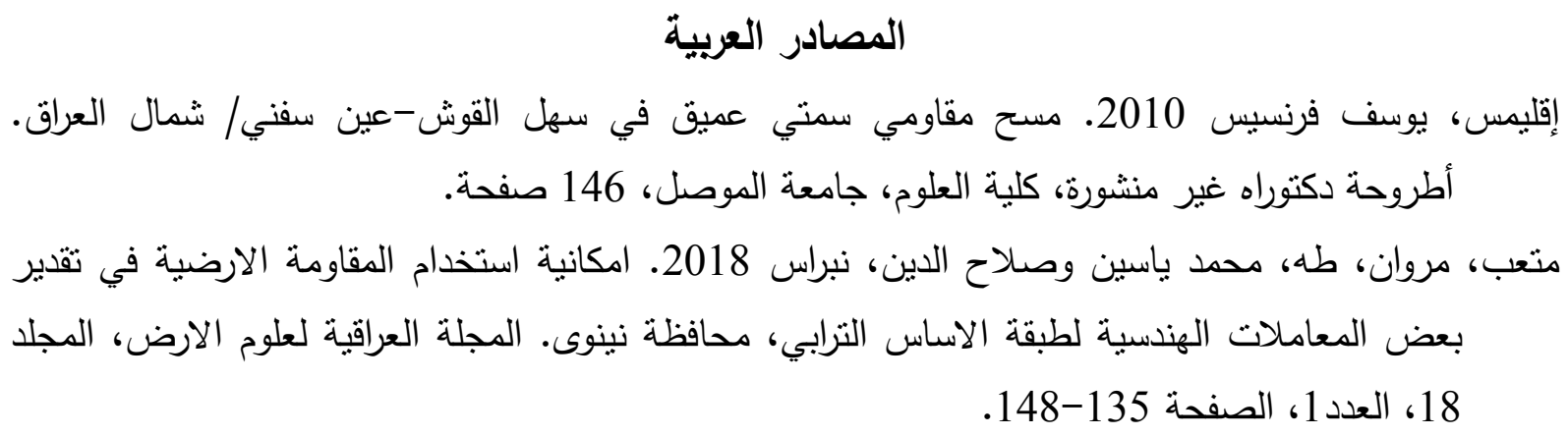

\section{المصادر الاجنبية}

Abdullahi, N.K., Batu, M.A. and Masanawa, A.A., 2012. Fracture determination using azimuthal, Schlumberger and offset Wenner array in basement complex of Northern Nigeria. Research Journal of Environment and Earth Sciences, Vol.4, No.7, pp.747-755.

Bayewu, O.O., Oloruntola, M.O., Mosuro G.O., Folorunso, I.O. and Kolawole, A., 2014. Evaluation of resistivity anisotropy of parts of Ijebu Igbo, Southwestern Nigeria using azimuthal resistivity survey (ARS) Method. Journal of Geography and Geology, Vol. 6, No. 4.

Boadu, F.K., Gyamfi, J. and Owusu, E., 2005. Determining subsurface fracture characteristics from azimuthal resistivity surveys: A case study at Nsawam, Ghana. Journal of Geophysics, Vol.70, No.5, pp. 35-42.

Busby, J. P., 2000. The effectiveness of azimuthal apparent resistivity measurements as a method for determining fracture strike direction. Journal of Geophysical Prospecting, Vol.48, pp. 677-695.

George, A.M. and Abong, A.A., 2014. DC Resistivity investigation of anisotropy and lateral effect using azimuthal offset wenner array. A case study of the University of Calabar, Nigeria. Journal of Environment and Earth Science, ISSN 2225-0948 (Online), Vol.4, No.1.

LandMapper Manual, 2012. Measuring Electrical Properties of Natural Systems with LandMapper® ERM-02. 68 p. www.landvisor.com

Odoh I.B. and Onwuemesi A.G. 2009. Estimation of anisotropic properties of fractures in Presco Campus of Ebonyi State University Abakaliki, Nigeria using azimuthal resistivity survey method. Journal of Geology and Mining Research, Vol. 1, No. 8, pp. 172-179.

Osinowo, O.O., Akanji, A.O. and Akinmosin, A., 2011. Integrated geophysical and geotechnical investigation of the failed portion of a road in basement complex terrain, Southwest Nigeria. RMZ-Materials and Geo-Environment, Vol. 58, No. 2, pp. 143-162. 
Rasul, H., Karlson, C., Jamali, I., Earon, R. and Olofsson, B., 2015. Geophysical methods for road construction and maintenance. Geophysical Research, Vol. 17, EGU2015-10603, 2015 EGU.

Sheriff, E. R., 2013. Encyclopedic dictionary of applied geophysics. Fourth edition.

Slater, L.D., Wishart, D.N. and Gates, E.A., 2006. Self-potential improves characterization of hydraulically active fracture from azimuthal geoelectrical measurements. Geophysical Res. Lett., 33, L17314.

Taylor, R.W., and Fleming, A.H., 1988. Characterizing jointed systems by azimuthal resistivity surveys. Journal of Ground water, Vol. 26, pp. 464-474.

Victor, E. and Mamah, L., 2014. Geophysical investigation of road failure the case of Opoji in Nigeria. International Journal of Scientific and Engineering Research, Vol. 5, Issue 1, pp.1769-1779.

Watson, K.A. and Barker, R.D., 2002. Use the offset Wenner technique to characterize a single dipping interface. European Journal of Environment and Engineering Geophysics,Vol. 7, pp.103-120.

Watson, K.A. and Barker, R.D., 1999. Differentiation anisotropy and lateral effects using azimuthal resistivity offset Wenner soundings. Journal of Geophysics, Vol. 64, pp. 739-745. www.iiste.org. 